\title{
En el extremo de la Zona Cantábrica (Artículo de divulgación basado en una conferencia dictada por el autor, en Arbejal, Palencia, a profesores de Enseñanza Media)
}

\author{
At the Cantabrian zone edge \\ (Dissemination article based on a lecture given by the author, in Arbejal, \\ Palencia, to Secondary Education teachers)
}

\author{
Jenaro L. García-AlCalde ${ }^{\mathrm{I}}$ \\ ${ }^{1}$ Departamento de Geología, Universidad de Oviedo, C/ Jesús Arias de Velasco s/n, 33005 Oviedo, España \\ (email: jalcalde@geol.uniovi.es)
}

Resumen: Se describe a grandes rasgos la evolución paleogeográfica y estructural y las condiciones tectonosedimentarias de la Zona Cantábrica, durante las etapas Variscas preorogénica y sinorogénica, con foco principal en la Provincia del Pisuerga-Carrión, y se detalla algo más la estratigrafía del Devónico de la región y las huellas que dejaron en las rocas de esta edad diferentes eventos geo-biológicos con elevado interés como herramientas cronoestratigráficas.

Palabras clave: paleogeografía, evolución tectonosedimentaria, Zona Cantábrica, provincia del Pisuerga-Carrión, orogenia Varisca, Silúrico-Carbonífero.

Abstract: An overall description of the Variscan paleogeography and tectonosedimentary evolution of the Pisuerga-Carrión Province (eastern Cantabrian Zone, N Spain) is given. The Devonian stratigraphy of that province and the major geologic and paleontological events recorded in these successions are briefly discussed, emphasizing their significance as chronostratigraphic tools.

Keywords: paleogeography, tectonosedimentary evolution, Cantabrian Zone, Pisuerga-Carrión province, Variscan orogeny, Silurian-Carboniferous. 
La primera vez que recorrí la montaña palentina, en el borde oriental de la Zona Cantábrica (Fig. 1), quedé impresionado por su carácter áspero y solitario, dilatadas y bellísimas perspectivas y acceso relativamente sencillo, aunque no tardé en cambiar de opinión sobre el último aspecto tras algunas duras experiencias en las laderas de Peña Prieta y Curavacas (Fig. 2). Y si las primeras sensaciones, puramente estéticas, de los paisajes y lugares que atravesaba ya me habían enamorado, su geología me subyugó hasta resolverse en una relación permanente con el área que se ha prolongado por más de quince años.

La Zona Cantábrica es un territorio de grandes contrastes, debido a la compleja orografía que pasa, de norte a sur, en pocos quilómetros, de estrechas franjas litorales planas a una nutrida alternancia de valles y sierras que van ganando altura hasta alcanzar cotas por encima de $2500 \mathrm{~m}$ en las vertientes hidrográficas fronterizas entre Asturias, Galicia, León y Santander, y entre Palencia, León, Santander y Burgos.

Las líneas que siguen pretenden ofrecer un relato sucinto, estrictamente divulgativo, de la geología de los terrenos paleozoicos del norte de Palencia, en la llamada Provincia del Pisuerga-Carrión (Julivert, 1971) (denominada, alternativamente, Dominio Palentino por diferentes autores), de acuerdo con el siguiente guión:

a) Situación paleogeográfica, es decir dónde y en qué condiciones se encontraba la zona durante el Paleozoico y, en especial, del Silúrico al Carbonífero, hace 420-320 millones de años.

b) Evolución tectonoestratigráfica en el contexto de la dinámica cantábrica general con descripción algo más detallada de las unidades preorogénicas.

c) Descripción y análisis de algunos fenómenos particulares, ligados a la evolución de la vida, que dejaron huellas especialmente notables en el Devónico de la región.

\section{Evolución paleogeográfica y estructural}

La Provincia del Pisuerga-Carrión se encuentra en el extremo oriental de la Zona Cantábrica dentro del Macizo Ibérico. Por ello, su desarrollo geológico

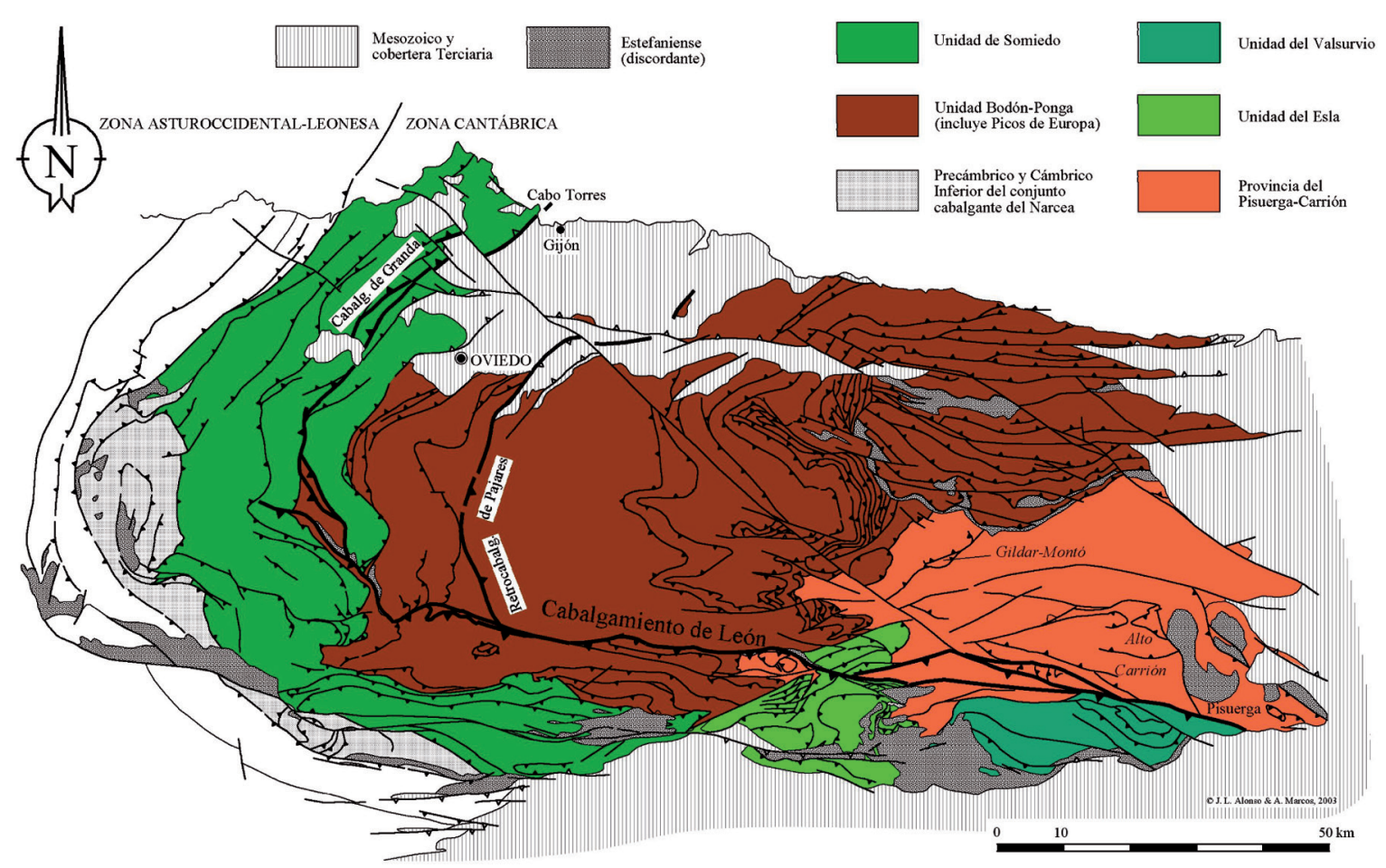

Figura 1: Situación de la Provincia del Pisuerga-Carrión en la Zona Cantábrica (figura cedida por J. L. Alonso y A. Marcos, con mínimos añadidos). Cabalg: Cabalgamiento. 


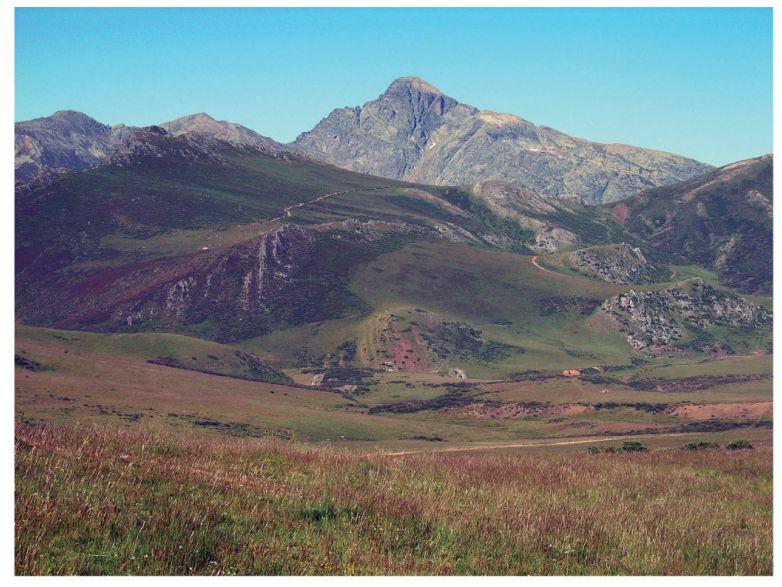

A

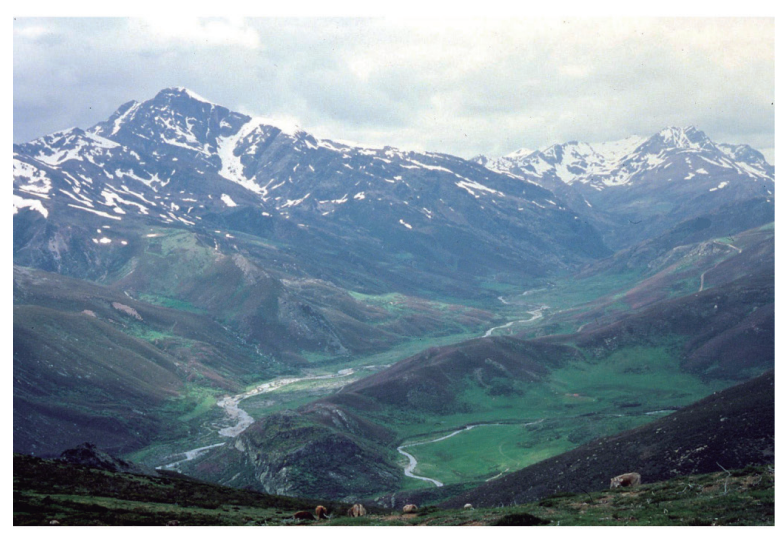

B

Figura 2: A) Núcleo del sinclinal de Cortes, en el Alto Arauz (Mantos Palentinos); al fondo, el Pico Curavacas (2524 m), localidad tipo del Conglomerado de Curavacas, del Moscoviense. B) Valle del río Carrión, al pie de la Sierra de Curavacas.

fue parte del proceso general de formación del Macizo pero, en razón de su posición, la deformación comenzó aquí algo más tarde que en el resto de la Zona.

Esto me lleva a comentar los principales rasgos tectónicos de la Cordillera Cantábrica. Trataré de hacerlo con la mayor sencillez, aunque se trata de un proceso complejo que requiere una visualización fuertemente movilista.

La evolución tectonoestratigráfica en el norte de España fue relativamente tranquila durante parte del Paleozoico (Cámbrico-Ordovícico), hace 500 a 450 millones de años. En esta Arcadia feliz, todo el área noroccidental de la Península estaba cubierta por mares poco profundos que recibían los materiales erosionados de un antiguo macizo emergido que se extendía desde el centro de Asturias hasta el actual Mediterráneo (Macizo Cántabro-Ebroico, de Carls, 1983). La deformación, en esta lejana época, se manifestó principalmente en la aparición de fracturas directas formando escalones estructurales hacia occidente (Aramburu et al., 1992).

A partir de algún momento del Paleozoico Inferior, la aproximación de Gondwana (la placa tectónica donde viajaba Iberia) a otros continentes hizo que las condiciones de deformación se tornasen compresivas, con la línea de esfuerzo principal hacia oriente. De manera que en el Devónico Superior, hace alrededor de 360 millones de ańos, se invirtió el relieve desapareciendo el Macizo Cántabro-Ebroico bajo los depósitos sinorogénicos cantábricos: las tierras emergidas pasaron ahora a estar situadas al oeste de la Zona Cantábrica y la cuenca marina al este.

Durante el Carbonífero, a comienzos de la llamada Orogenia Varisca, la propagación de la deformación (relacionada con el movimiento de aproximación de los continentes) determinó en la Provincia del Pisuerga-Carrión la formación y desplazamiento de un conjunto de láminas cabalgantes (mantos). Y si se me permite la broma, tomada de la letra de un viejo tango, «este fué su único pecado y por el se condenó»: la enorme complejidad del Dominio Palentino deriva de esta situación dinámica. Las láminas cabalgantes se fueron engrosando por delante creando y empujando cuñas sedimentarias procedentes de la erosión del frente de las propias láminas y del arrastre de depósitos previos (ver, por ejemplo, Colmenero et al., 2002). De esta manera, la Provincia del Pisuerga-Carrión quedó «cogida entre fuegos cruzados», afectada por cabalgamientos provenientes del sudoeste: Mantos Palentinos y Unidades de Somiedo, Valsurvio, Esla y Bodón-Ponga (Alonso et al., 2009), que alcanzaron la región en diferentes momentos del Carbonífero, y, más tarde, en la parte alta del período, las láminas cabalgantes de los Picos de Europa que se movieron hacia el sudeste contribuyendo de forma importante a la formación del Arco Ibero-Armoricano y de su expresión cantábrica: el Arco Astúrico. 
Las cuñas sedimentarias desplazadas, en continuo cambio, formaron finalmente, discordancias, sistemas de pliegues de vergencias variadas, depósitos desorganizados, etc. en una trama casi inextricable (Rodríguez Fernández y Heredia, 1987; Heredia et al., 1990). Imagínense un escuadrón de palas mecánicas con motores de diferente potencia en movimiento de aproximación hacia un vertedero, arrastrando cada una su propio montón de escombros, algunas acelerando, otras frenando y retomando, más tarde, la marcha, y piensen en el batiburrillo final que formarían sus cargas al llegar a destino. La estratigrafía sinorogénica de la Provincia del Pisuerga-Carrión, es justo ese batiburrillo. Cada parte de la cuenca -cada lugar del vertedero- muestra un argumento propio, relacionado con la cuña o cuñas clásticas que afluyeron allí. Todo ello, hace que sea muy difícil correlacionar las distintas series estratigráficas lo que ha conducido a una proliferación impresionante de nombres de discordancias y unidades (grupos, formaciones, miembros) (Rodríguez Fernández et al., 1987; Heredia et al., 1990, Rodríguez Fernández et al., 1994, entre otros), frente a la que los propios especialistas se muestran, con frecuencia, perplejos.

¡Y la historia no acaba ahí! Después de una fase relativamente tranquila, al término de la Orogenia Varisca, en el curso de la cual prácticamente todos los continentes terrestres se agruparon en uno solo llamado Pangea, las masas continentales volvieron a romperse y a moverse, separándose unas de otras hasta alcanzar la geografía actual. La apertura del océano Atlántico provocó la convergencia de África y Eurasia dando lugar a la llamada Orogenia Alpídica que levantó cordilleras como los Pirineos, los Alpes, los Himalayas y otras más a lo largo de la antigua faja ecuatorial. En el norte de España, esta etapa dinámica se manifestó como una serie de esfuerzos dirigidos hacia el sur que contribuyeron a la exhumación del basamento varisco y a la creación del moderno relieve (Espina, 1994; Alonso et al., 1996; Gallastegui, 2000). La Orogenia Alpídica se evidencia marcadamente en el límite meridional de la Cordillera Cantábrica, donde los estratos mesozoicos se encuentran levantados hasta alcanzar la vertical e, incluso, invertidos hacia el sur, como puede verse en varias localidades palentinas (Alonso et al., 1996, Pulgar et al., 1999) (Fig. 3).
Volviendo a los Mantos Palentinos, durante el Namuriense arrastraron hacia el nordeste solo la parte superficial y más moderna de las secuencias paleozoicas razón por la que, hoy día, el nivel de erosión no alcanza a descubrir rocas más antiguas que las del Silúrico. Estas láminas cabalgantes pudieron formar parte de un importante relieve submarino, desarrollado más cerca de la costa por el apilamiento de otras láminas rocosas, el llamado Domo del Valsurvio, pero se deslizaron, quizás por gravedad, por el escarpe septentrional del Domo hasta emplazarse en la cuenca palentina. Estos movimientos ocurrieron a mediados del Carbonífero, durante al Moscoviense inferior, hace alrededor de 310 millones de años. En este proceso, las láminas cabalgantes perdieron contacto con su origen, el cual debe encontrarse hoy bajo el enorme espesor de sedimentos recientes de la Meseta Castellana (Frankenfeld, 1983; Marquínez y Marcos, 1984).

En principio, el orden estratigráfico interno de los Mantos Palentinos es normal, es decir, las rocas más antiguas de cada lámina se encuentran por debajo de las más modernas, y su composición viene determinada por el nivel estratigráfico en el que despegaron de la masa de rocas de procedencia. Los paquetes de lutitas y algunas calizas muy plásticas sirvieron habitualmente como horizontes de despegue. Las primeras unidades cabalgantes partieron, con frecuencia, de niveles más profundos (habitualmente lutitas del Silúrico) y provocaron en su movimiento, la formación de otras escamas más adelantadas en niveles cada vez más modernos, del Devónico al Carbonífero Inferior. El apilamiento final muestra así láminas con niveles de despegue más antiguos superpuestas a otras que despegaron en niveles más modernos. Sin embargo, hay zonas como el área del Gildar-Montó (Marquínez y Marcos, 1984) donde la disposición de las láminas parece seguir la llamada «regla de la diverticulación» con las láminas transportando sucesivamente tramos más antiguos de la secuencia estratigráfica, lo que denotaría un origen gravitacional para las mismas (Figs. 4A, B). La erosión diferencial, causada por las escorrentías, actuando preferentemente sobre las rocas más blandas, permitió, a veces, la exhumación de algunas de estas estructuras de superposición que constituyen llamativos ejemplos de klippes, ventanas y semiventanas tectónicas (Fig. 5). 

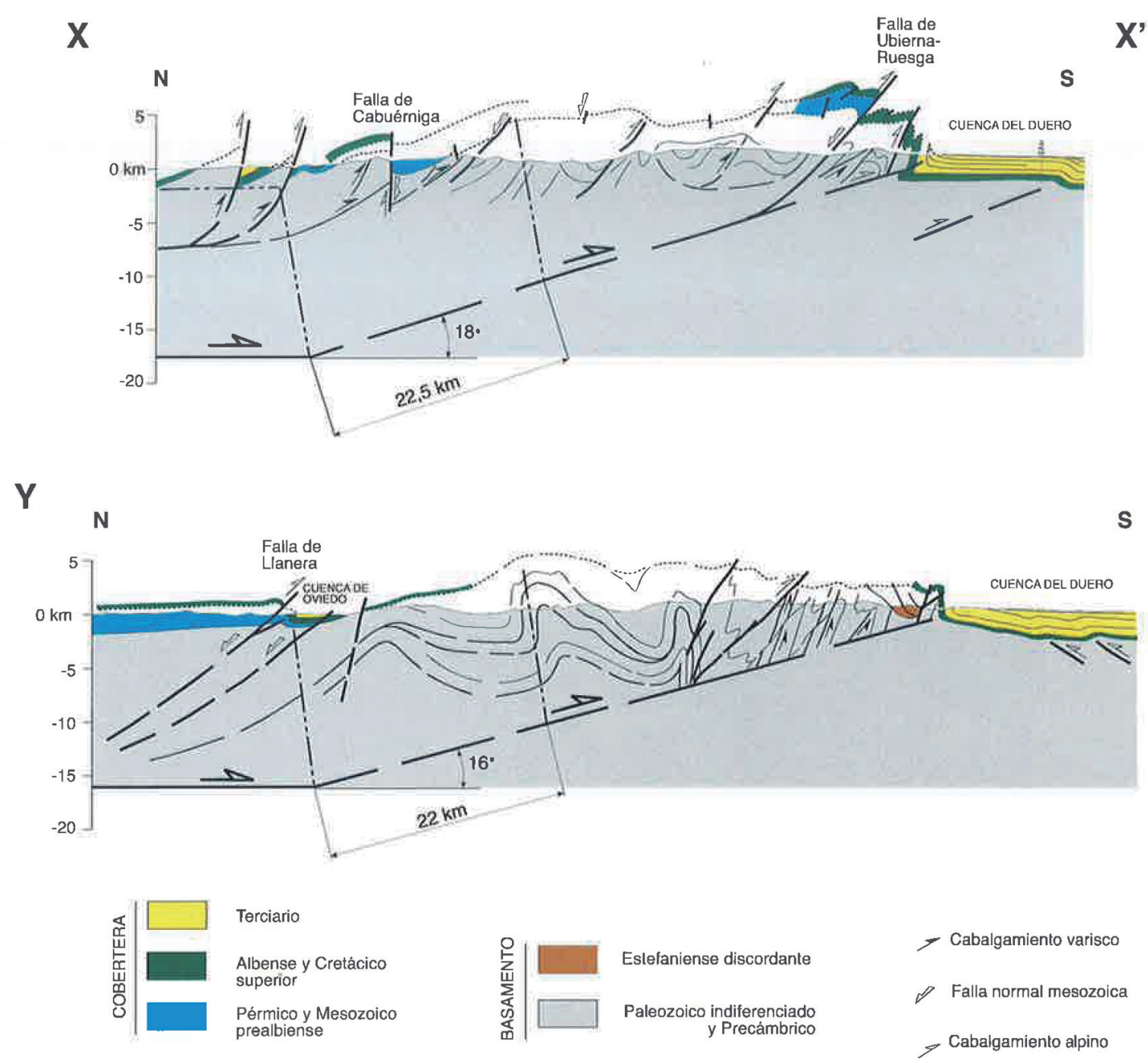

Figura 3: Cortes norte-sur de la Zona Cantábrica mostrando la deformación Alpina que afecta a la sucesión Mesozoico-Terciario de la Meseta llegando a invertir la serie (tomado de Pulgar et al., 1999, con autorización).

La deformación producida durante el resto del Carbonífero complicó el modelo al plegar y fracturar las láminas, causando una gran compartimentación y cambios extremos en la inclinación de las estructuras.

En el curso del desplazamiento hacia el nordeste de las unidades del Domo del Valsurvio y del Manto del Esla, la denudación de importantes relieves topográficos creados más al sur de la Provincia del Pisuerga-Carrión originó una espesa sucesión sedimentaria comprendiendo espectaculares masas de cantos rodados cementados: el llamado Conglomerado de Curavacas, principalmente cuarcítico, y otros depósitos de edad Moscoviense, de origen fluvial o flu- vio-deltaico, que cubren discordantemente parte de los Mantos Palentinos (Rodríguez Fernández y Heredia, 1988).

\section{La estratigrafía del Dominio Palentino}

En razón de la compartimentación tectónica, los afloramientos de rocas preorogénicas de la Provincia del Pisuerga-Carrión están separados por importantes fallas y cabalgamientos. Sin embargo, en general, el aspecto de las distintas formaciones se mantiene relativamente constante, lo que acredita la homogeneidad de las condiciones genéticas, aunque se registra una pérdida de potencia de sur a norte. 


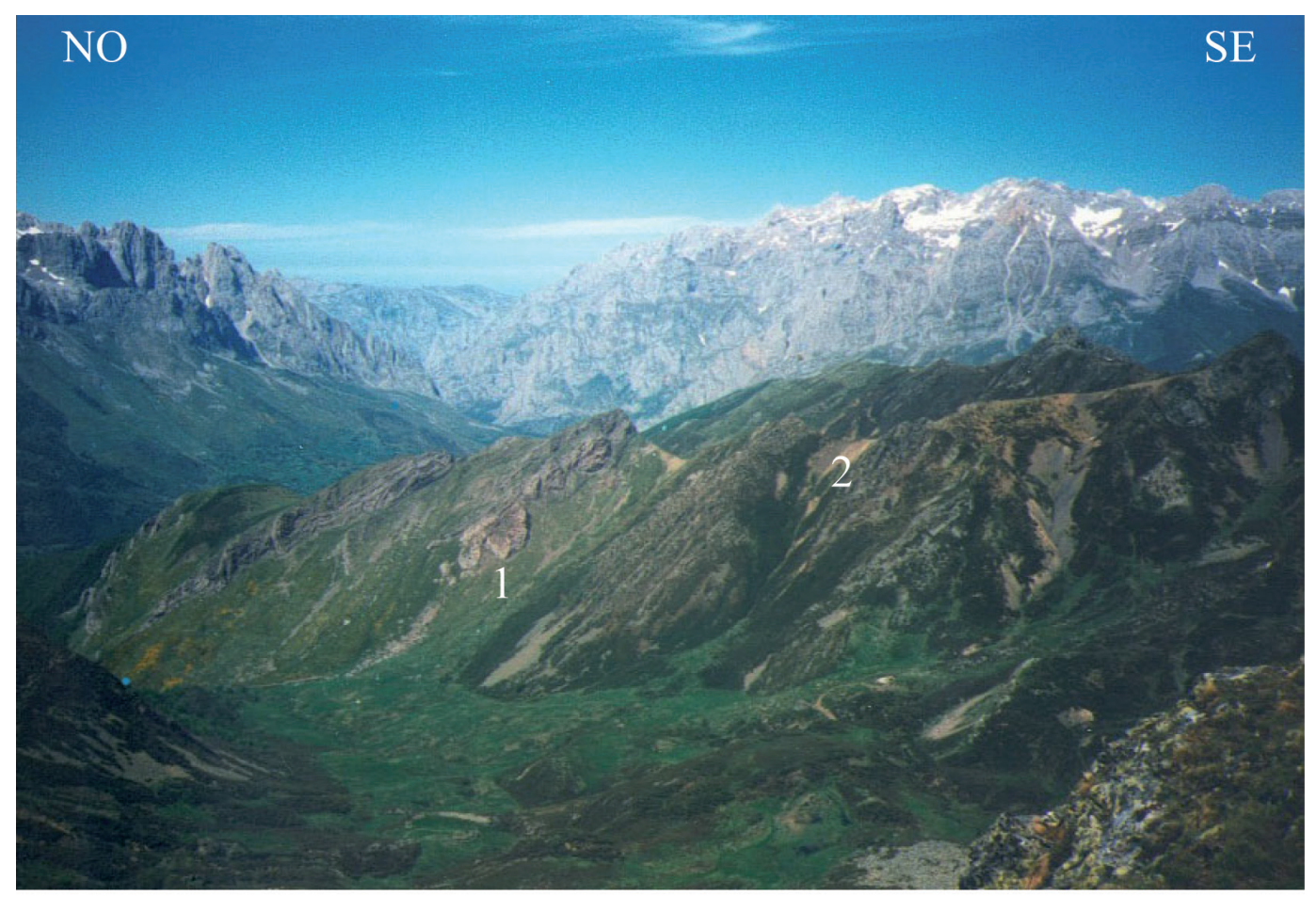

A

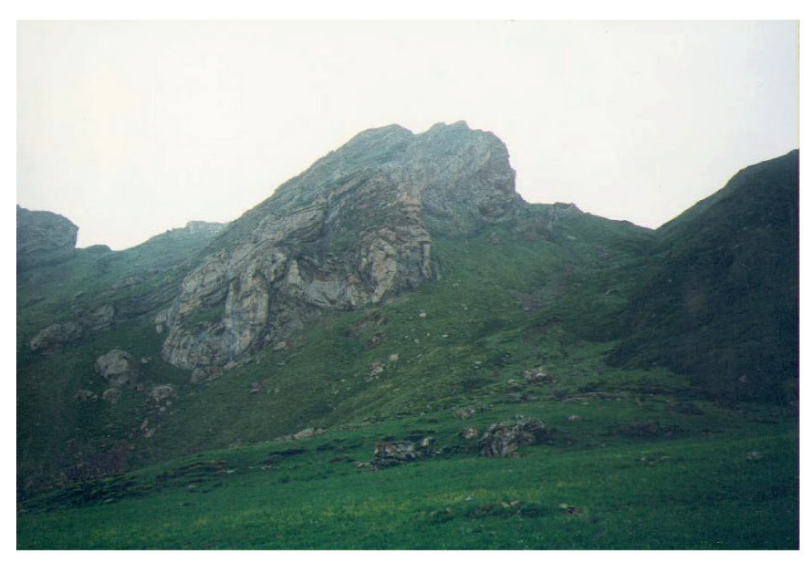

B

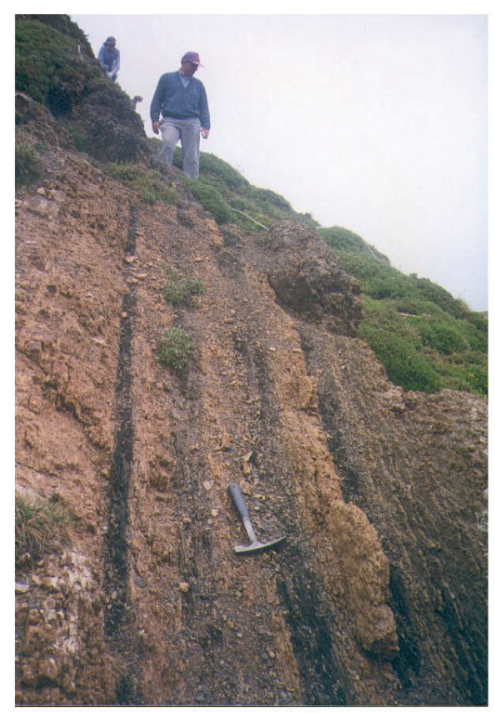

$\mathrm{C}$

Figura 4: A) Perspectiva desde el Pico Gildar, mirando al NNE, de las láminas cabalgantes, posiblemente gravitacionales, de la unidad del Gildar-Montó en la Sierra de Peńaquebrada. Al fondo, los Picos de Europa. 1: Pliegues asociados al cabalgamiento meridional de la Horcada del Oro (ver mapa, cortes e interpretaciones en Marquínez y Marcos, 1984). B) Detalle de los pliegues (1) de la fotografía A. C) Desarrollo estratigráfico del Evento Kellwasser Inferior (LKE) en el collado al sur de Peńaquebrada (punto 2 de la fotografía A). En la foto pueden observarse las lutitas nodulosas de la parte superior de la Formación Cardaño e intercalaciones de lutitas negras. 


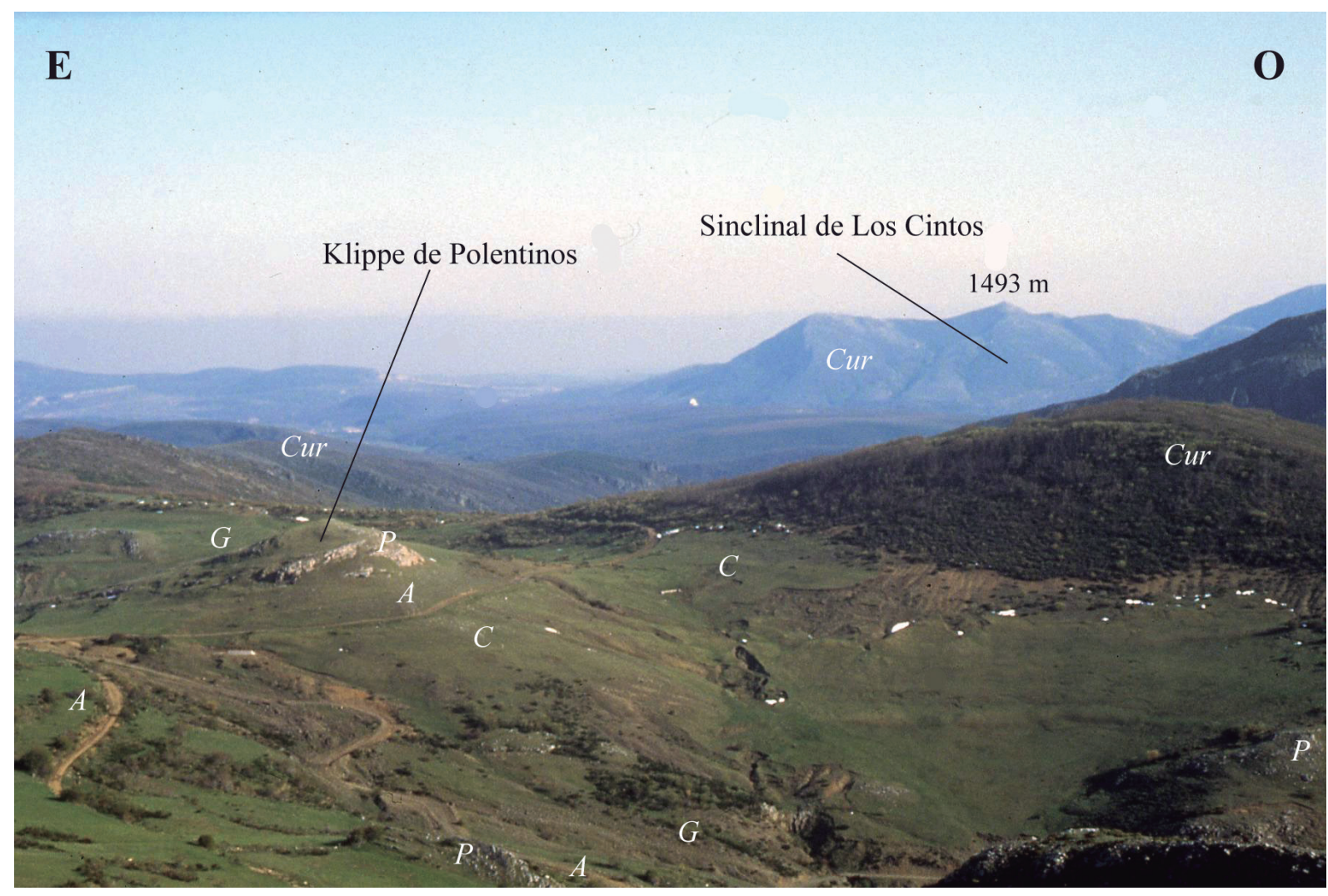

Figura 5: Vista hacia el sur desde el Collado de La Pedrosa. A la izquierda, terminación occidental del Klippe de Polentinos. En segundo término, afloramiento de los Conglomerados de Curavacas del sinclinal de Los Cintos. A, C. G. P: Formaciones devónicas Abadía, Cardaño, Gustalapiedra y Polentinos. Cur: Conglomerado carbonífero de Curavacas.

Estas rocas se formaron, como ya se dijo, en los mares que rodeaban el antiguo Macizo Cántabro-Ebroico, probablemente en la llamada Zona Asturoccidental-Leonesa, al Sudoeste del Dominio Palentino (Frankenfeld, 1983).

Durante el Silúrico Superior la profundidad de la cuenca fue escasa y el tipo de rocas derivadas se parece mucho en todo el área. Sin embargo, a partir del Emsiense (Devónico Inferior, hace unos 400 millones de años) se produjo una clara diferenciación batimétrica, con el ámbito Palentino situado en el borde externo de la plataforma y el Astur-Leonés, en posición mas cercana a la costa, lo que produjo rocas y fósiles muy distintos en ambas regiones. Las condiciones volvieron a homogeneizarse durante el Carbonífero inferior pero divergieron de nuevo hacia la parte final de este período, con depósitos sinorogénicos muy espesos y marcadas variaciones espaciales y temporales.
Las rocas más antiguas visibles hoy en el Dominio Palentino, son del Silúrico Superior y comprenden típicamente areniscas, cuarcitas y lutitas. Durante el Devónico, se acumuló allí un espesor total de alrededor de $900 \mathrm{~m}$, claramente inferior al del Dominio Astur-Leonés (sobre $2000 \mathrm{~m}$ ), debido a la procedencia más alejada de la costa de los depósitos del Dominio Palentino. El Devónico palentino comprende una alternancia de episodios carbonatados y pelíticos, estos últimos más importantes que en el ámbito Astur-Leonés, pero hacia el techo de la sucesión apareció una formación relativamente espesa: las Cuarcitas de Murcia (Fig. 6), de origen posiblemente turbidítico, cuya génesis parece preludiar el comienzo de la Orogenia Varisca.

Los fósiles de la mayor parte de formaciones devónicas palentinas responden a la situación batimétrica pelágica en que vivieron los seres de los que proceden, con presencia de abundantes ammonoideos, dacrioconáridos y trilobites (Figs. 7, 8 y 9) que per- 


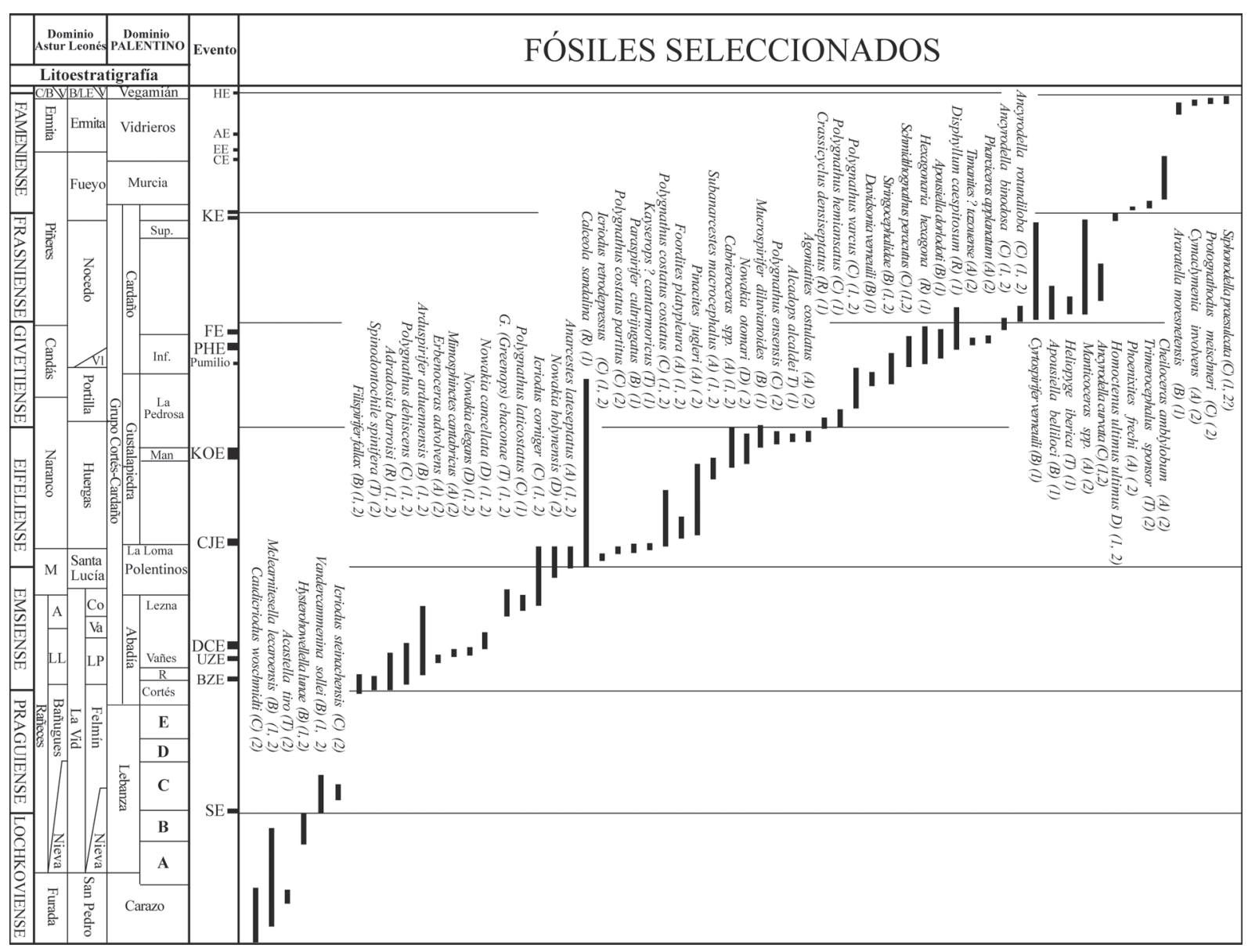

Figura 6: Cronoestratigrafía, bioestratigrafía y correlación de las unidades litoestratigráficas de Asturias, León y Palencia, mostrando la posición de los principales eventos geo-biológicos del Devónico (modificado de García-Alcalde et al., 2002).

miten excelentes correlaciones temporales con zonas equivalentes de todo el mundo.

El nombre y la edad de las formaciones del Devónico, así como su correlación a lo largo de la Zona Cantábrica, se incluye en la figura 6. Trabajos paleontológicos importantes (ver bibliografías en ellos), son los de Adrichem-Boogaert (1967), Garcia-López (en Sanz-López et al., 1999a, b y en García-López et al., 2002) y Raven (1983): conodontos, Arbizu (1977, 1985, 2001) y Smeenk (1983): trilobites, Becker (1981): ostrácodos, Binnekamp (1965) y García-Alcalde (1998b, 2004, 2010, 2013, 2014): braquiópodos, García-Alcalde et al. (1988, 1990a, b): síntesis de los elementos paleontológicos más importantes de la Provincia del Pisuerga-Carrión, Kullmann (1960), Montesinos (1987, 1988, 1991), Montesinos y Arbizu (1987) y Montesinos y Sanz-
López (1997): ammonoideos, Mader (1986): pisciformes y Truyols-Massoni (1988, 1989, 1999a, b): dacrioconáridos.

El Silúrico comprende las espesas formaciones siliciclásticas de Robledo, Arroyacas y Carazo (800-900 $\mathrm{m}$, en total), del Wenloquiense superior al Lochkoviense inferior, con importantes faunas de braquiópodos, trilobites y palinomorfos en ciertos niveles de la sucesión (cf. Jahnke et al., 1983, Schweineberg, 1987). A finales del Silúrico, el abundante aporte de arenas de la Fm. Carazo, cesó abruptamente y desde la parte media del Lochkoviense inferior se estableció en toda la región una plataforma carbonatada somera origen de la Formación Lebanza (alrededor de 160 $\mathrm{m}$ principalmente de carbonatos muy fosilíferos) que prevaleció hasta bien arriba del Praguiense (Fig. 6). Es destacable que en la mitad superior de la Fm. Le- 

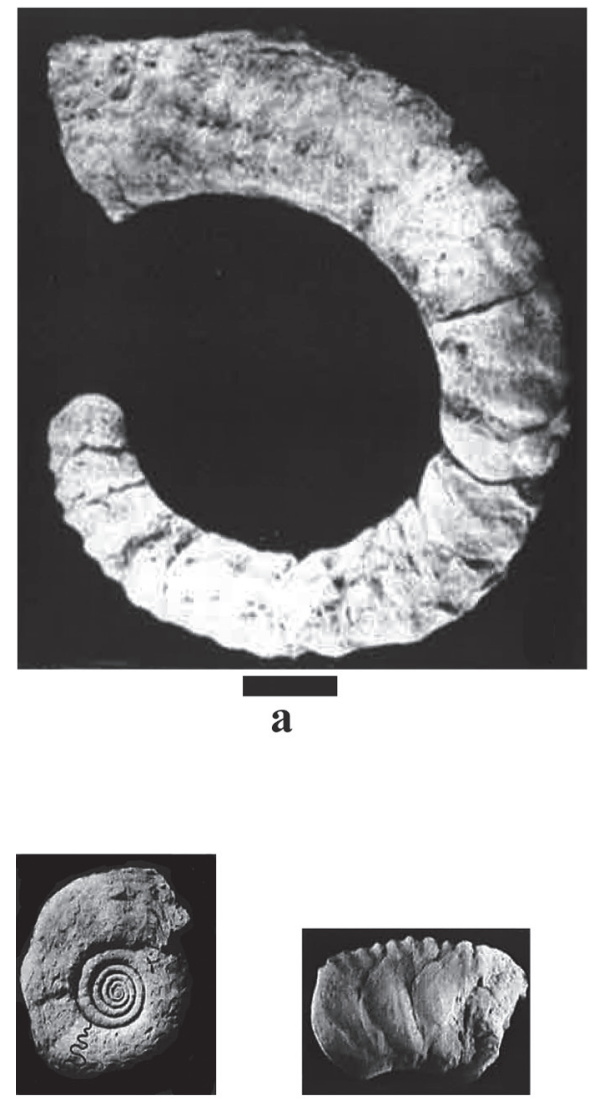

$\mathbf{e}$

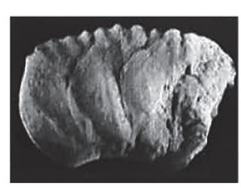

f

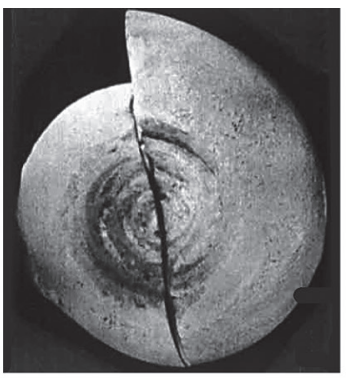

b

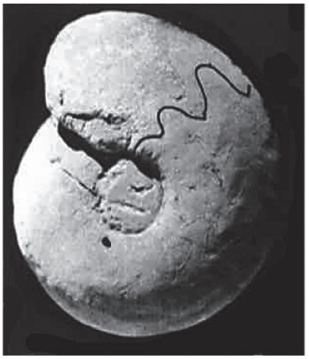

C

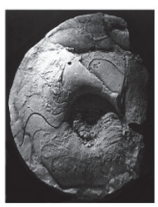

g

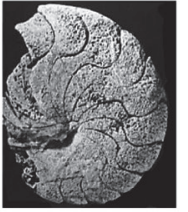

h

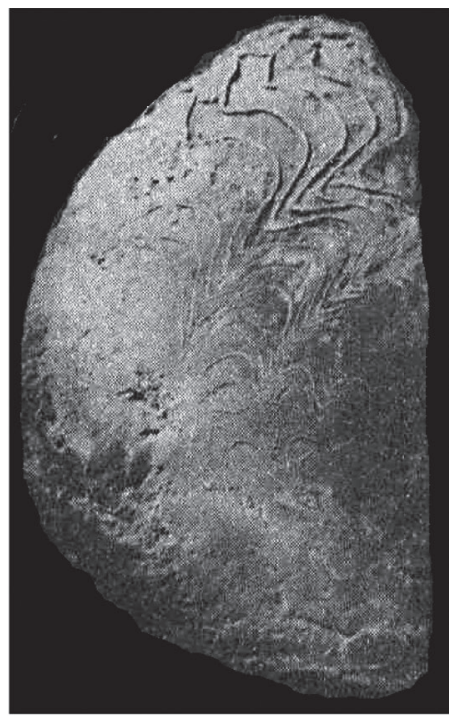

d

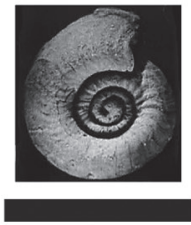

i

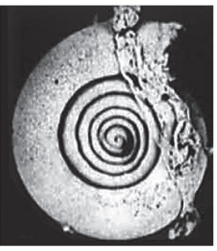

j

Figura 7: Algunos ammonoideos significativos del Devónico del Dominio Palentino. a) Erbenoceras filalense (Termier y Termier), Emsiense inferior (parte alta); b) Anarcestes lateseptatus (Beyrich), Emsiense superior; c) Pharciceras applanatum Bensaid, Frasniense inferior; d) Timanites? taouzense (Petter), Frasniense; e) Schindewolfoceras alcaldei Montesinos y Henn, Frasniense; f) Mimosphinctes cantabricus Kullmann, Emsiense inferior (parte alta); g) Manticoceras sp., Frasniense; h) Tornoceras cantabricum Montesinos, Givetiense; i) Agoniatites costulatus (Archiac y Verneuil), Eifeliense terminal; j) Cabrieroceras devians Chlupac y Turek, Eifeliense superior. Barra de escala pequeña: $10 \mathrm{~mm}$. Barra grande (solo para figuras i y j): $5 \mathrm{~mm}$ (fotografías tomadas de R. Montesinos, 1988, con autorización).

banza se desarrollaron los primeros montículos arrecifales coralinos de la Zona Cantábrica (Soto et al., 2007). Hacia el techo de la Formación Lebanza entraron en la cuenca aportes siliciclásticos finos en proporción creciente. Estos aportes llegaron a substituir por completo a las calizas, dando lugar a la llamada Fm. Abadía (Praguiense-Emsiense superior) (Fig. 6) cuya potencia alcanza los 150-200 m. En ella, se observa la presencia de faunas mixtas: pelágicas y neríticas, a base de dacrioconáridos (Biozona de Nowakia zlichovensis, Fig. 8), ammonoideos, trilobites, corales solitarios y braquiópodos. En su primera mitad, la formación contiene un delgado (alrededor de $15 \mathrm{~m}$ ), pero muy constante nivel carbonatado formado por las calizas del Miembro Requejada (R, en Fig. 6); esta unidad es importante para reconstruir las sucesiones locales de la Fm. Abadía la cual, en razón de su escasa competencia general, se encuentra muy tectonizada constituyendo ella misma la base de muchos de los niveles de despegue de los Mantos Palentinos. Un rasgo notable es que inmediatamente sobre la caliza de Requejada aparecen los ammonoideos más antiguos de la Zona Cantábrica y quizás de España: se trata de la llamada «Fauna de Anetoceras» perteneciente a la Biozona de dacrioconáridos Nowakia elegans (Figs. 6, 7 y 8), del Emsiense inferior; forman parte de ella taxones con enrollamientos incompletos, como Erbenoceras y otros con enrollamientos poco apretados como Mimosphinctes (Fig. 7f), Celaeceras, Mimagoniatites y otros (Montesinos, 1991). 


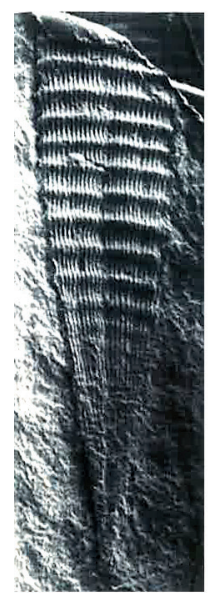

$\mathbf{a}$
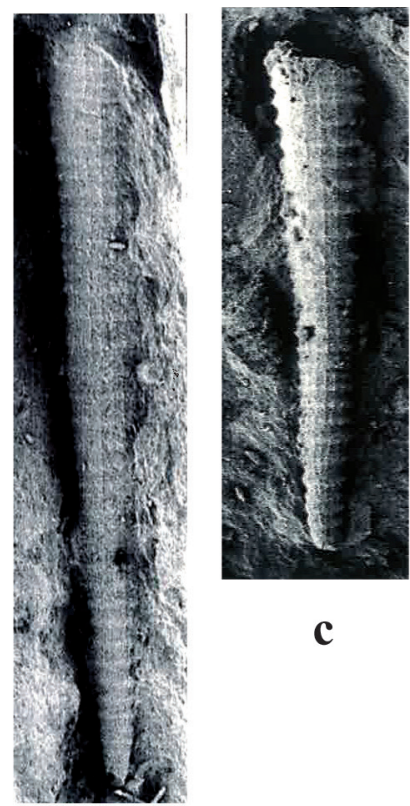

c
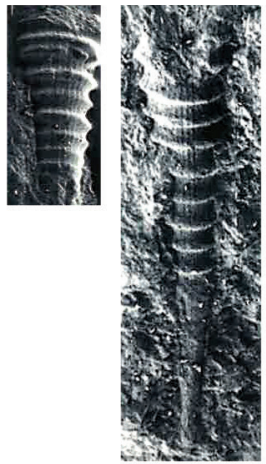

d
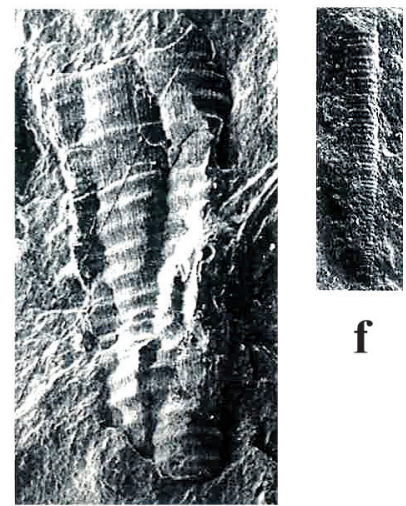

$\mathbf{e}$

\section{$3 \mathbf{~ m m}$}

b

Figura 8: Algunos Tentaculitoideos interesantes del Devónico del Dominio Palentino. a) Nowakia zlichovensis Boucek, Emsiense inferior; b) Nowakia elegans (Barrande), Emsiense inferior (parte alta); c) Nowakia cancellata Boucek, Emsiense superior; d) Dos ejemplares de Nowakia holynensis Boucek, Emsiense superior (parte alta); e) Nowakia otomari Boucek, Eifeliense superior; f) Homoctenus ultimus derkaouensis Lardeux, Frasniense superior (fotografías tomadas de Truyols-Massoni, 1988, con autorización).

La Fm. Polentinos (Emsiense inferior-Eifeliense inferior) (Fig. 6) es otro episodio carbonatado, poco potente $(60 \mathrm{~m})$ pero generalizado, desarrollado principalmente en la Biozona de dacrioconáridos Nowakia holynensis (Fig. 8), con faunas neríticas y pelágicas relativamente pobres, aunque con importantes episodios de bioturbación que dejaron facies notables de Zoophycos y otros icnofósiles.

La Fm. Gustalapiedra (Eifeliense inferior-Givetiense inferior) (Fig. 6), comprende 50-60 m de lutitas negras y lentejones escasos de calizas arcillosas y nodulosas. La fauna con dacrioconáridos, ammonoideos, trilobites y braquiópodos es principalmente pelágica. La mitad superior de la formación integra un miembro delgado (4-5 m), muy constante, de limolitas y areniscas de grano fino, con intercalaciones de pizarras negras, el Miembro Man (Fig. 6), cuya importancia para la correlación de las sucesiones de la formación es equivalente a la del Mb. Requejada en la Fm. Abadía.

La Formación Cardaño (Givetiense medio-Fameniense más bajo) (Fig. 6), de unos $75 \mathrm{~m}$ de poten- cia, es difícil de distinguir de la anterior salvo por el desarrollo, en la parte baja y cerca del techo, en medio de una sucesión predominantemente lutítica, de episodios carbonatados nodulares de cierto espesor. Comprende faunas pelágicas de dacrioconáridos y homocténidos, así como ammonoideos multilobulados (Fig. 7) y otros.

En la parte alta de la sucesión devónica, se produce un marcado cambio litológico representado por la Formación Murcia (Fameniense inferior) (Fig. 6), un potente depósito $(100-150 \mathrm{~m})$, probablemente turbidítico, de areniscas cuarcíticas y cuarcitas, en bancos gruesos a muy gruesos separados por intercalaciones de lutitas negras y numerosos episodios conglomeráticos de grano fino. A lo largo de la formación aparecen nuevas faunas de ammonoideos (Cheiloceratidae, sobre todo, bivalvos, ostrácodos, braquiópodos y trilobites (Figs. 6, 7 y 9).

La Formación Vidrieros (Fameniense inferior-Carbonífero basal) (Fig. 6) comprende $50 \mathrm{~m}$ de calizas nodulosas rojizas y lutitas oscuras intercaladas, con fauna abundante y variada de ammonoideos (Chei- 


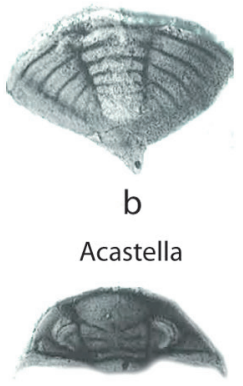

a

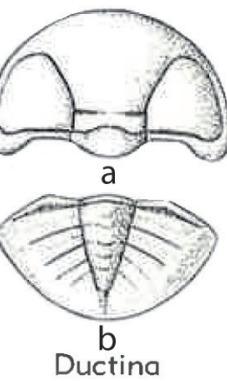

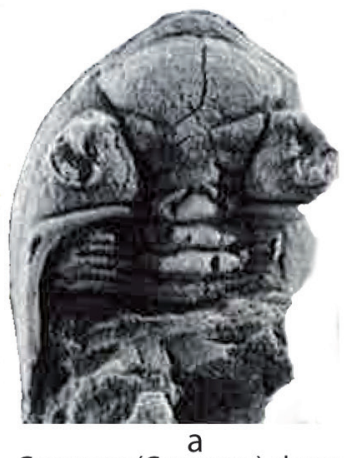

Greenops (Greenops) chaconae
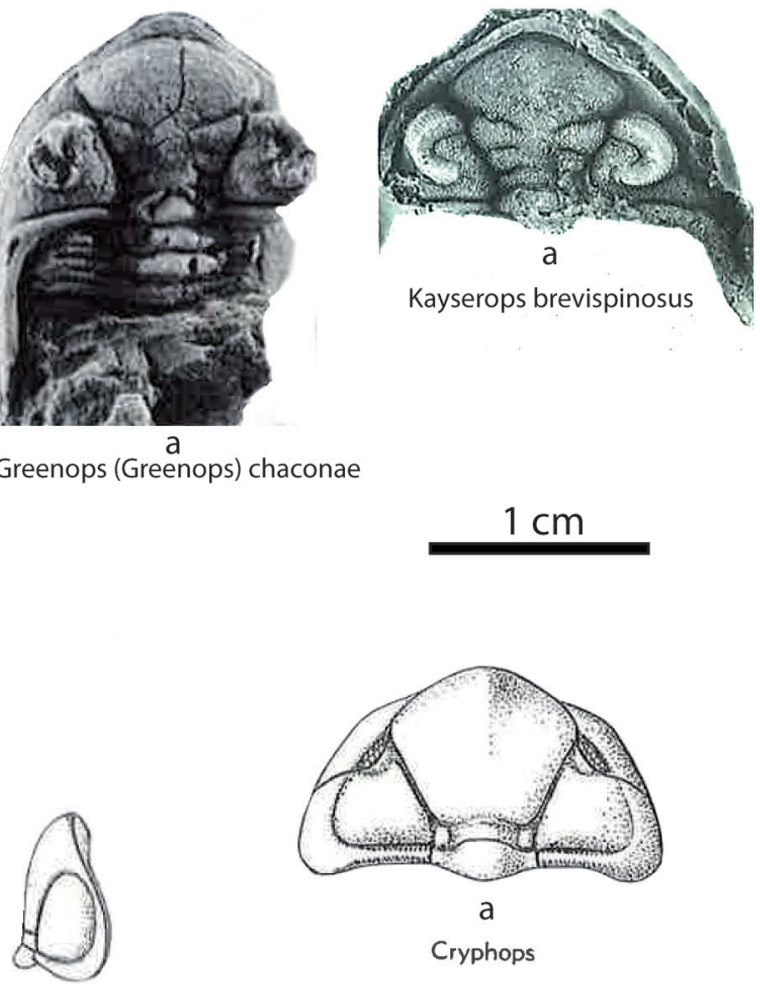

C

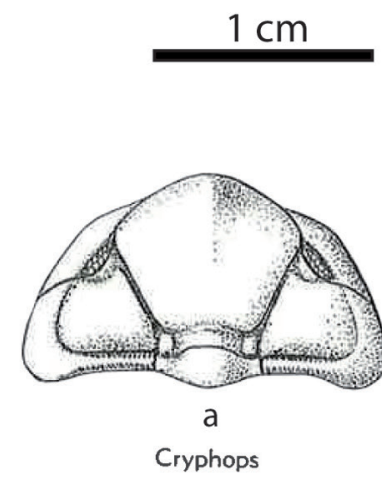

Cryphops

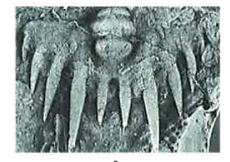

b

Leonaspis aff. pigra

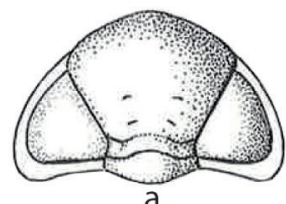

a
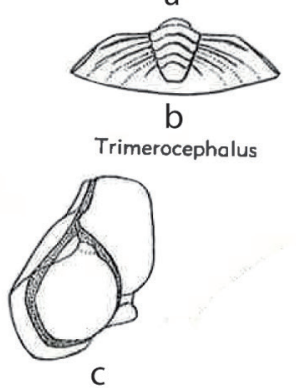

Figura 9: Algunos trilobites significativos que aparecen en el Dominio Palentino. Acastella, Greenops (Greenops), Kayserops y Leonaspis, tomados de Smeenk (1983). Ductina, Cryphops y Trimerocephalus, tomados de Harrington et al. (1959).

loceratidae y Clymenida) y algunos trilobites (Fig. 9), bivalvos y braquiópodos.

Los efectos de la Orogenia Varisca comenzaron a manifestarse en toda la Cordillera a partir del Devónico Superior, pero las formaciones carboníferas más antiguas: (Vegamián y Alba también denominada Genicera), de presencia casi generalizada en la región son consideradas por algunos autores, como depósitos pre-orogénicos (Rodríguez-Fernández y Heredia, 1987). La Fm. Vegamián (Turnesiense) (Fig. 6), es un paquete de alrededor de $40 \mathrm{~m}$ de lutitas negras y liditas con nódulos silicofosfatados y delgados lentejones de calizas arcillosas negras, con conodontos, ammonoideos, ostrácodos y trilobites. La Fm. Alba (Viseense-Namuriense inferior) situada por encima, es menos constante que la anterior y está formada por un conjunto de 15 a $25 \mathrm{~m}$ de calizas nodulosas rojas, frecuentemente brechificadas, y lutitas, con faunas relativamente abundantes de goniatítidos y prolecanítidos. Por encima, en algunas áreas de la Provincia aparece la Caliza de Montaña (integrada por las formaciones Barcaliente y Valdeteja que, a veces, se denominan con diferentes nombres locales), una espesa sucesión carbonatada del Serpujoviense-Bashkiriense, substituida en buena parte del Pisuerga-Carrión por rocas predominantemente siliciclásticas con denominaciones muy diversas en la literatura geológica (ver, por ejemplo, Rodríguez Fernández y Heredia, 1987; Martin-Merino et al., 2014 y sus referencias bibliográficas).

Desde mediados del Carbonífero (hace unos 320 millones de años), la inestabilidad general de la región provocó de nuevo una fuerte compartimentación sedimentaria propiciando la formación de sucesiones coetáneas diferentes en las distintas partes de la cuenca. Situación que, una vez más, contribuyó a incrementar la nutrida agenda de nombres de formaciones que aparecen en la literatura geológica, complicando la nomenclatura estratigráfica regional. La transición entre las condiciones preorogénicas y sinorogénicas plenas suele situarse entre la Caliza de Montaña y el Conglomerado de Curavacas o formaciones equiva- 
lentes (cf. Martin-Merino et al., 2014), un conjunto rocoso con espesores cercanos a $3000 \mathrm{~m}$. La propia Formación Curavacas, separada en la mayor parte de la región de las formaciones subyacentes por una importante discordancia (Discordancia Palentina, o Curavacas, según Kanis, 1956) alcanza su espesor máximo (más de $1000 \mathrm{~m}$, en la montańa que le da nombre: el Pico Curavacas (Fig. 2).

La potencia de la sucesión sinorogénica post-discordancia de Curavacas (de edad Moscoviense superior) es también muy grande en algunas áreas, alcanzando, por ejemplo, cerca de $3000 \mathrm{~m}$ en el llamado dominio del Yuso. Dicha sucesión está frecuentemente constituida por rocas turbidíticas integradas en lóbulos de abanicos submarinos. Los restos fósiles son escasos y consisten en algunas pistas (icnofósiles) y en las fusulinas que aparecen en algunos cuerpos calcáreos. Estos últimos parecen corresponder a depósitos de plataforma continental deslizados e incorporados a las turbiditas del pie del talud (olistolitos). Finalmente, los materiales más modernos del Carbonífero cantábrico, cuya edad va del Moscoviense terminal al Gzeliense, se encuentran, a su vez, discordantes sobre los anteriores (Discordancias Leónica y Astúrica) y son, al menos en parte, rocas postorogénicas resultantes de la erosión de la Cordillera Varisca. Dichas rocas se disponen formando parches aislados, sin continuidad cartográfica, condicionados casi siempre por la existencia de fracturas variscas previas, que llegaron a formar paleorelieves más o menos acusados, principalmente subaéreos. Cerca de la localidad de Guardo y al este del río Pisuerga, los materiales sinorogénicos más modernos y los postorogénicos tempranos comprenden una nutrida alternancia de episodios marinos y continentales que totaliza más de $6000 \mathrm{~m}$ de espesor rocoso.

\section{Eventos geo-biológicos}

El estudio de sucesos geológicos que tuvieron un impacto importante sobre la distribución y abundancia de los seres vivos sobre la Tierra y, en particular, los que provocaron extinciones y apariciones a escala global de muchos y diversos grupos de organismos (extinciones y radiaciones masivas) en períodos geológicamente breves, constituye una aproximación estratigráfica cada vez más apreciada para conseguir correlaciones de alta precisión, unas correlaciones sobre las que, a menudo, se apoya la definición formal de unidades cronoestratigráficas (García-Alcalde, 1998a). En el Devónico casi todos los bioeventos de este tipo se reconocieron primero en el dominio facial pelágico. De ahí que las rocas preorogénicas de la Provincia del Pisuerga-Carrión que pertenecen, en buena medida a dicho ámbito, tengan una importancia estratigráfica sobresaliente.

Investigaciones como la mencionada, requieren técnicas estratigráficas de reconocimiento a lo largo y ancho de las series estratigráficas así como otros estudios y mediciones complementarias, geoquímicas y geofísicas, cuyo objetivo es llegar a reconocer las causas primeras de los bioeventos y, en su caso, correlacionarlas a escala global. En estudios recientes sobre el Devónico de la Cordillera Cantábrica se aplicó, con buenos resultados, una técnica geofísica especial: el llamado análisis de eventos de susceptibilidad magnética y cicloestratigrafía (método MSEC) (Crick et al., 1997). El método consiste en medir la susceptibilidad magnética de las rocas inducida mediante impulsos eléctricos. La susceptibilidad refleja la concentración de partículas magnéticas que depende de la tasa de sedimentación en relación con la eustasia, el clima y la subsidencia de las cuencas marinas. En general, en rocas marinas, sobre todo hemipelágicas y pelágicas, las tendencias MSEC hacia valores crecientes de susceptibilidad se relacionan con episodios de regresión, mientras que las tendencias opuestas lo hacen con episodios transgresivos.

Las sucesiones devónicas del Pisuerga-Carrión, aportan importantes datos. Estos datos, expuestos de modo amplio en García-Alcalde et al. (1990a), Truyols-Massoni et al., (1990), García-Alcalde (1997, 1998a), García-Alcalde et al. (2001) y García-Alcalde et al. (2002), entre otros, se recogen a continuación de manera resumida

1) Evento Sulcatus (Evento Lochkoviense/Praguiense, $S E)$ (Fig. 6, 10 y11). En Bohemia y otras regiones, la transición entre los Pisos Lochkoviense y Praguiense se sitúa algo por encima de la base de la Biozona de conodontos Eognathodus sulcatus, coincidiendo con la variación de coloración de las rocas a tonos más claros, indicando una regresión generalizada y rápida y con cambios paleontológicos importantes. En Pa- 


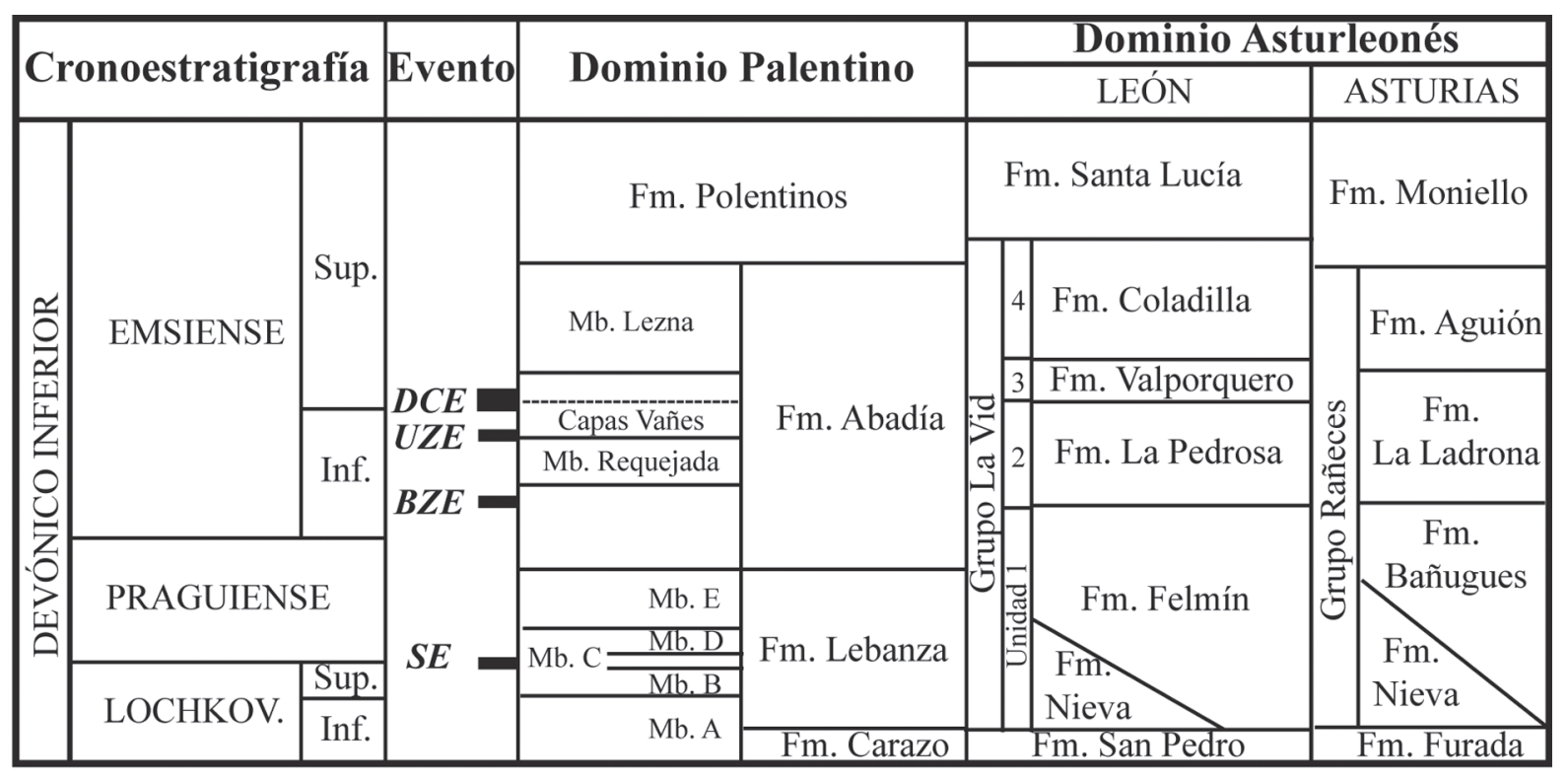

Figura 10: Correlación de los eventos geo-biológicos del Devónico Inferior en la Zona Cantábrica (N de España). Lochkov: Lochkoviense. Inf: Inferior; Sup: Superior. Fm: Formación; Mb: Miembro.

lencia, no pudieron identificarse ni la especie-guía, E. sulcatus, ni otros conodontos importantes para la correlación. De manera que el evento se reconoce, en principio, por la marcada variación de color de las rocas en la parte media de la Fm. Lebanza, fenómeno acompañado de modificaciones faunísticas y presencia de una anomalía MSEC positiva (Fig. 10) del mismo carácter e intensidad que la identificada desde Chequia hasta Marruecos en niveles de edad similar. Los cambios paleontológicos consisten en la existencia de varios relevos faunísticos, entre los que cabe destacar la aparición de géneros de braquiópodos como Vandercammenina e Hysterolites, a partir de formas de Howellella (Hysterohowellella) y H. (Iberohowellella). El desarrollo de los primeros montículos arrecifales coralinos del Devónico, en el Praguiense, que en el dominio nordogonwánico acredita la deriva de todo el área a posiciones tropicales, se asocia también con otra importante anomalía MSEC positiva (Fig. 11) presente asimismo en otras sucesiones de España y norte de África, de similares condiciones paleoecológicas.

2) Evento Zlichoviense basal (BZE) (Figs. 6 y 10). En Bohemia, este evento se caracterizó como un evento local, de escasa importancia. Sin embargo, en el Dominio Palentino podría estar representado por una fuerte transición litológica que se puede observar en la parte inferior de la Formación Abadía (Calizas del Miembro Requejada) y parece denotar un pulso transgresivo de incidencia supra-regional. El evento registra una importante proliferación de trilobites y el desarrollo claro de la llamada "Fauna de Cyathaxonid», de corales rugosos solitarios (Soto y Kullmann, 1996).

3) Evento Zlichoviense superior (UZE) (Figs. 6, $10 \mathrm{y}$ 12). Este evento, el más marcado del Zlichoviense, podría coincidir con el pulso global Ib de Johnson et al. (1985) o una fase del mismo (Ib3, en García-Alcalde, 1997), algo más antigua que el importante Evento Daleje-Cancellata (Ib4, de Johnson et al., 1985), con el que se confunde a menudo. El cambio litológico no es muy neto, pero la huella bioestratigráfica sí lo es, incluyendo la primera radiación importante de ammonoideos no bactrítidos. Este nuevo grupo, apareció en la Biozona de dacrioconáridos Nowakia zlichovensis (parte superior de la de Polygnathus dehiscens, en la escala de conodontos) (Truyols-Massoni, 1989) (Fig. 8a) y, después de una rápida evolución desde formas girocónicas y advolutas (la llamada "Fauna de Anetoceras»), con las vueltas separadas o en contacto parcial (Figs. 7a, f), alcanzaron la morfología enrollada normal. En el Dominio Palentino, el evento se reconoce por encima de las Calizas de Requejada, en las llamadas 

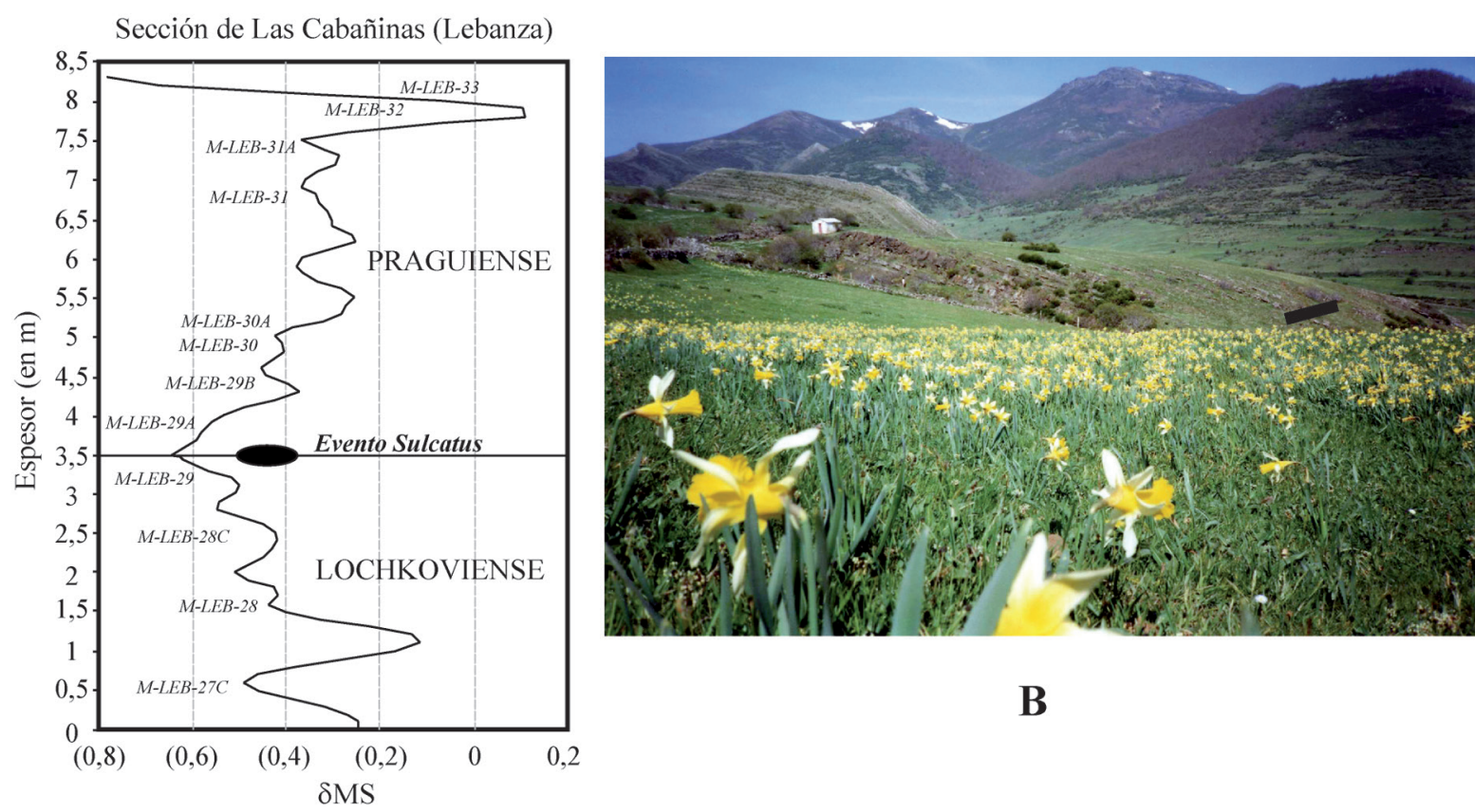

B

A

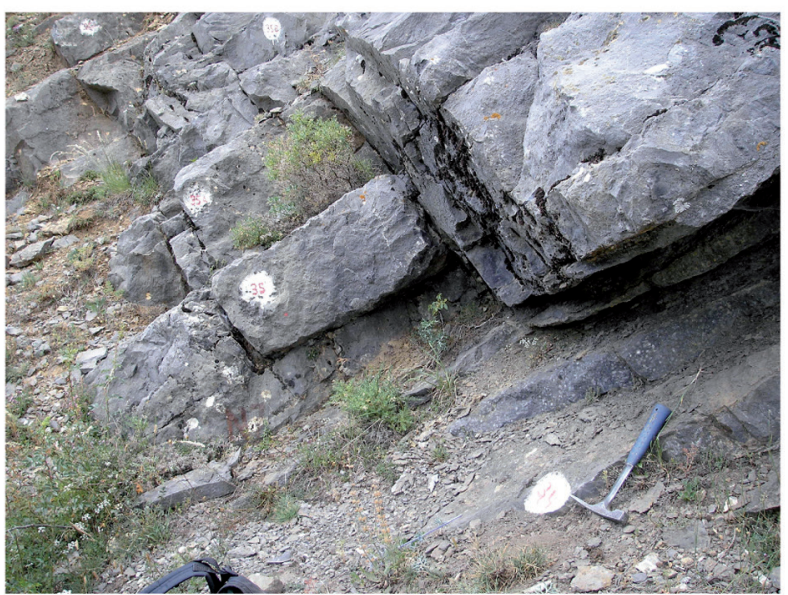

C

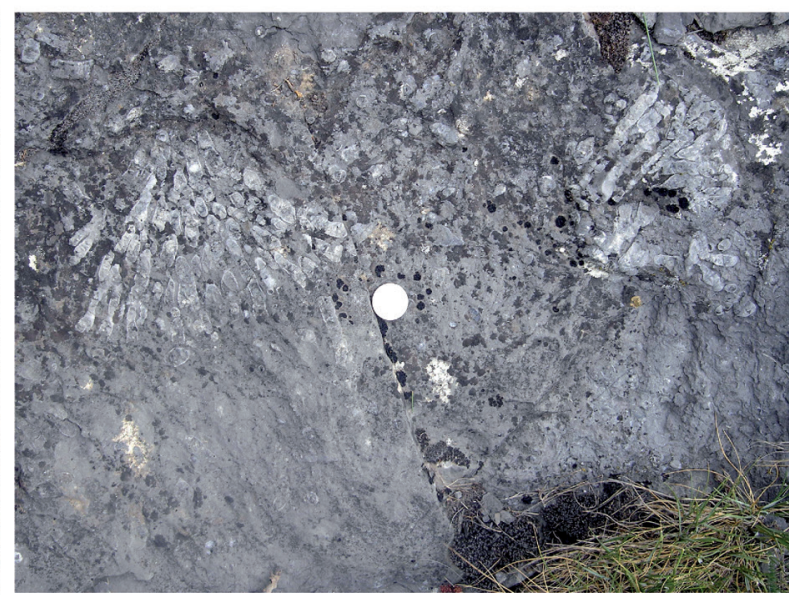

D

Figura 11: A) Curva MSEC de la sucesión de la Formación Lebanza en el afloramiento de la fotografía B mostrando la situación de la anomalía negativa (barra negra), del Evento Sulcatus (SE). B) Corte-tipo de la Fm. Lebanza (corte de Las Cabañinas), en el valle del Arroyo de la Abadía de Lebanza. La cota más alta, al fondo, es la Peña Carazo (2013 m). Barra negra: muestreo de susceptibilidad magnética entre los miembros B (superior) y C (inferior) de esta formación (Ver Fig. 6). C) Parte alta del Miembro C de la Formación Lebanza, mostrando el parche arrecifal más antiguo que se conoce en el Devónico de la Zona Cantábrica; las faunas corresponden a corales rugosos coloniales disfílidos. D) Detalle del Miembro C de la Fm. Lebanza donde se observan colonias coralinas fosilizadas en posición de vida.

«Capas de Vañes» (Figs. 6 y 10), donde hay también numerosos nautiloideos ortocónicos y trilobites facópidos, junto con elementos coralinos de la «Fauna de Cyathaxonia», menos abundantes y diversos que en las capas precedentes.
4) Evento Daleje-Cancellata (Devónico Inferior, transición Emsiense inferior-Emsiense superior, DCE) (Figs. 6,10 y 12). Este evento se reconoció gracias a los cambios litológicos y paleontológicos observados cerca de la base de la Formación Daleje, en Chequia. 


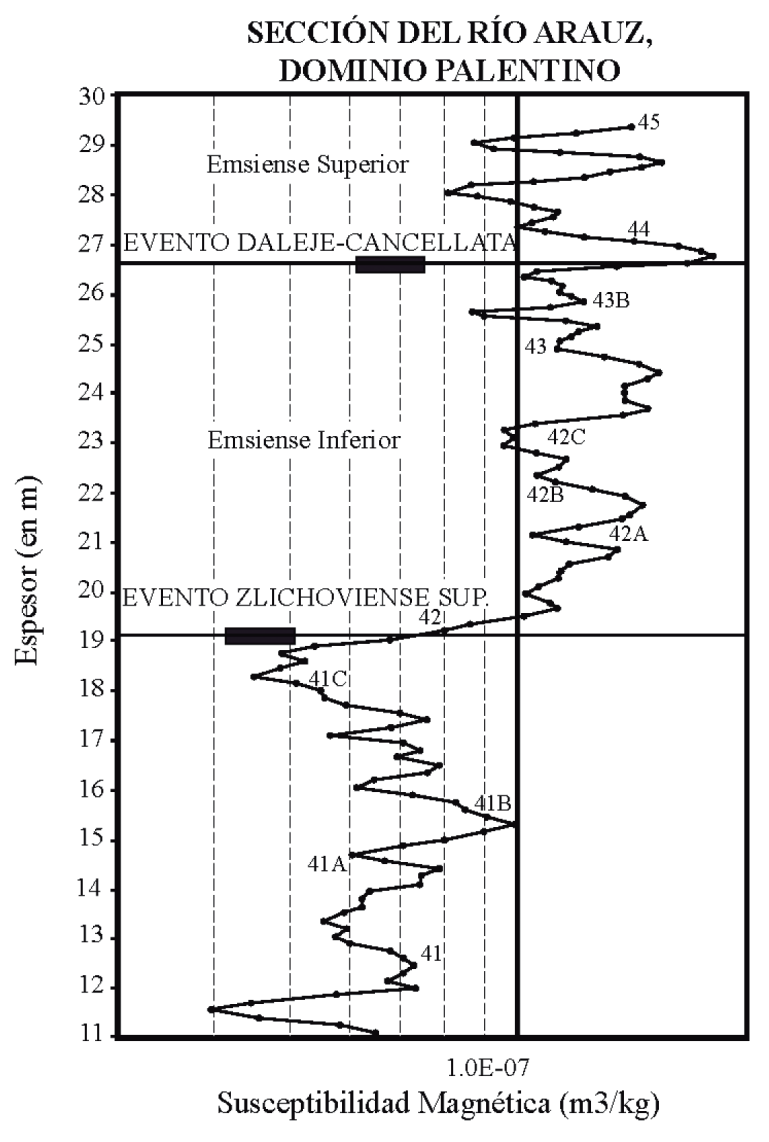

A

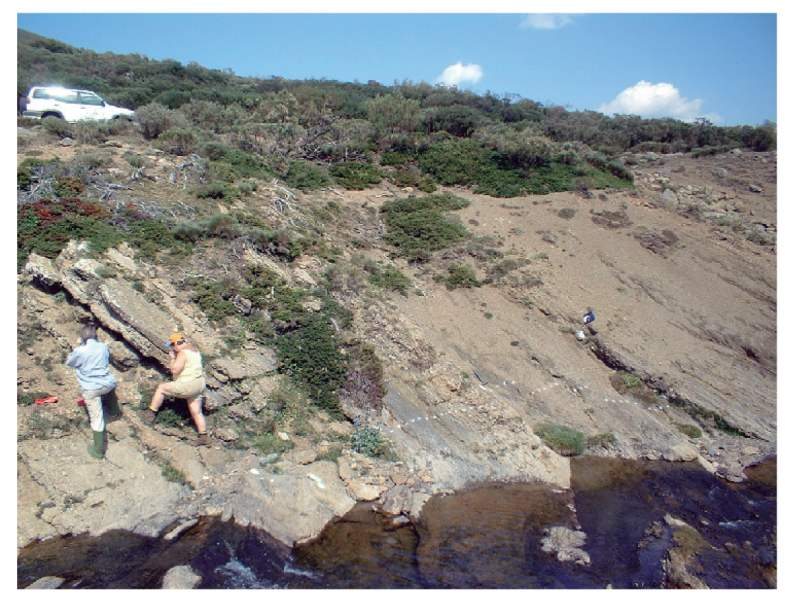

B
En esencia, el suceso corresponde a un pulso de profundización caracterizado por el reemplazamiento gradual de sucesiones de calizas y calizas margosas por lutitas oscuras a negras, con un acmé hacia el intervalo rocoso donde se registra la transición de las zonas de dacrioconáridos Nowakia elegans-Nowakia cancellata (Truyols-Massoni, 1989) (Figs. 8b, c). En términos paleontológicos, es un evento modesto donde se extinguen varios linajes de ammonoideos, como los Mimosphinctidae, y especies de Mimagoniatites observándose además pérdidas de diversidad en otros grupos bentónicos. La causa pudo ser una extensa anoxia en las plataformas continentales de todo el mundo. En las secciones del mundo muestreadas (incluyendo las palentinas) el evento geobiológico coincide con un pico muy acusado de los valores de susceptibilidad magnética (Ellwood et al., 2001) (Fig. 12A). Esta coincidencia se interpreta, igual que en el Evento SE (ver antes), como un fuerte argumento en favor del carácter global del fenómeno.

5) Evento Choteč -Jugleri (CJE) (Fig. 6). Tanto en facies litorales como pelágicas, este evento se manifiesta en la Zona Cantábrica por un cambio litológico en el que se pasa de calizas y dolomías de tonos claros a rocas lutíticas oscuras a negras con intercalaciones de calizas micríticas, margas, limolitas o areniscas (transición entre las formaciones Polentinos-Gustalapiedra, en el Dominio Palentino, Fig. 6). El cambio no es claramente perceptible en las curvas MSEC (Fig. 13), aunque parece asociado a un fenómeno de profundización de la cuenca en el límite de las Biozonas de conodontos Polygnatus costatus partitus/P. costatus costatus, algo por encima de la frontera Devónico Inferior-Medio (Emsiense/Eifeliense) (Ellwood et al., 2006). Los bioeventos relacionados son una importante variación de las asociaciones de ammonoideos (Montesinos, 1987) y una fase intensa de extinción de trilobites Asteropyginae y Proetidae (Arbizu, 1977, Smeenk, 1983) y corales de la «Fauna de Cyathaxonia».

Figura 12: A) Curva MSEC del intervalo de calizas nodulosas y lutitas situado sobre el Miembro Requejada de la Formación Abadía (Capas de Vañes, Fig. 6), mostrando las anomalías correspondientes a los eventos Zlichoviense Superior (UZE) y Daleje-Cancellata (DCE). 41, 41A, etc.: niveles de referencia del intervalo; pequeños círculos negros: muestras (modificado de Ellwood et al., 2001). B) Corte muestreado a lo largo del Río Arauz. Los puntos blancos sobre el corte, son los de toma de muestras de susceptibilidad magnética (SM) y corresponden a los puntos negros de la curva A. 


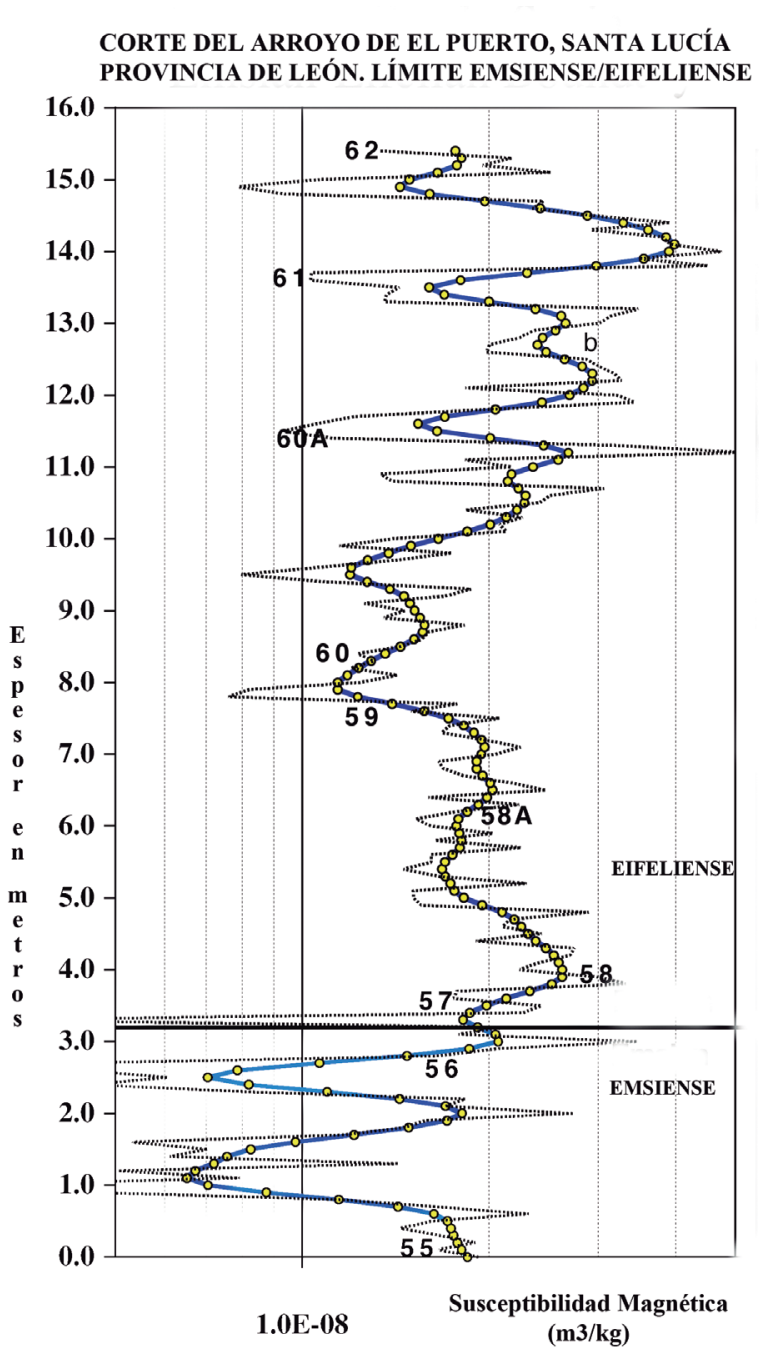

Figura 13: Curva MSEC de la transición Emsiense/Eifeliense en la Formación Santa Lucía, sección del Arroyo de El Puerto (provincia de León). El límite se encuentra algo por debajo del Evento Chotec-Jugleri. Números en la curva: niveles de referencia del corte; círculos amarillos: muestras tomadas (modificado de Ellwood et al., 2006).

6) Evento o Eventos Kačak-Otomari (KOE) (Fig. 6). El Evento (o Eventos) Kačak-Otomari (Schöne et al., 1998), se invocó como causa directa o indirecta de fenómenos tan importantes como la desaparición del llamado Dominio Paleobiogeográfico Malvino-Africano, achacada a un aumento significativo de la temperatura media global de los mares. Otra manifestación pudo ser el desarrollo de una importante laguna estratigráfica en el Devónico Medio (la Great Gap, de Struve, 1982). El fenómeno consistió, en esencia, en un prolongado episodio sedimentario anóxico (puesto de relieve por la presencia de luti- tas negras) que provocó varias etapas de extinción de conodontos, ammonoideos y de las comunidades bentónicas preexistentes. El fenómeno de extinción fue seguido de otro de radiación importante, al comienzo de la Zona de dacrioconáridos Nowakia otomari (Fig. 8e). Entre los ammonoideos aparecieron formas tan importantes como Cabrieroceras, Agoniatites, Holzapfeloceras, Wedekindella, Parodiceras y Maenioceras (Figs. 6 y 7) todas, menos la última, representadas en Palencia (Montesinos, 1988).

El evento coincide con una fuerte anomalía MSEC positiva localizada en la parte superior de un ancho valle de valores bajos que se muestra en la curva. $\mathrm{Ha}$ sido registrada en Marruecos, Francia y Alemania y en los cortes palentinos (Fig. 14), concretamente en la parte alta de la Fm. Gustalapiedra, en torno al Miembro Man (Fig. 6). El evento, o eventos, se registra en todo el mundo algo por debajo del límite Eifeliense-Givetiense de manera que, en ausencia de otros criterios, puede utilizarse para distinguir dicho límite.

Una característica muy importante del Evento Kačak-Otomari es que en Marruecos Ellwood et al. (2003) hallaron evidencias de su posible asociación con un impacto meteorítico similar, aunque no tan grande, como el que causó la extinción de los dinosaurios al final del Cretácico. En particular encontraron numerosos granos de cuarzo con señales de metamorfismo de choque, microtectitas (gotas de material fundido proyectadas por el impacto, solidificadas en contacto con la atmósfera), concentraciones altas de elementos infrecuentes en la corteza terrestre, pero bien conocidas en ciertos tipos de bólidos extraterrestres, como cobalto, vanadio, arsénico, cromo y níquel, y una gran anomalía negativa del isótopo estable C13, indicando una colosal eliminación de biomasa en el escalón trófico basal. Un dato muy importante es la existencia de indicios del mismo fenómeno en una sección (Aleje, León) de la Cordillera Cantábrica, en el Dominio Astur-Leonés (Ellwood, com. pers.), que se estudiarán en trabajos próximos.

7) Evento, o Eventos, Pumilio (Fig. 6). Desde hace tiempo se conoce en el Harz y en las Montañas Esquistosas Renanas (Alemania) un fenómeno de mortalidad en masa en el tercio medio del Givetiense, 
Sección compuesta del Mb. Man de la Fm. Gustalapiedra, en el arroyo de Man, cerca de la abadía de Lebanza, Palencia.
Sección compuesta del Mb. Man de la Fm. Gustalapiedra, en el collado de La Pedrosa, Palencia

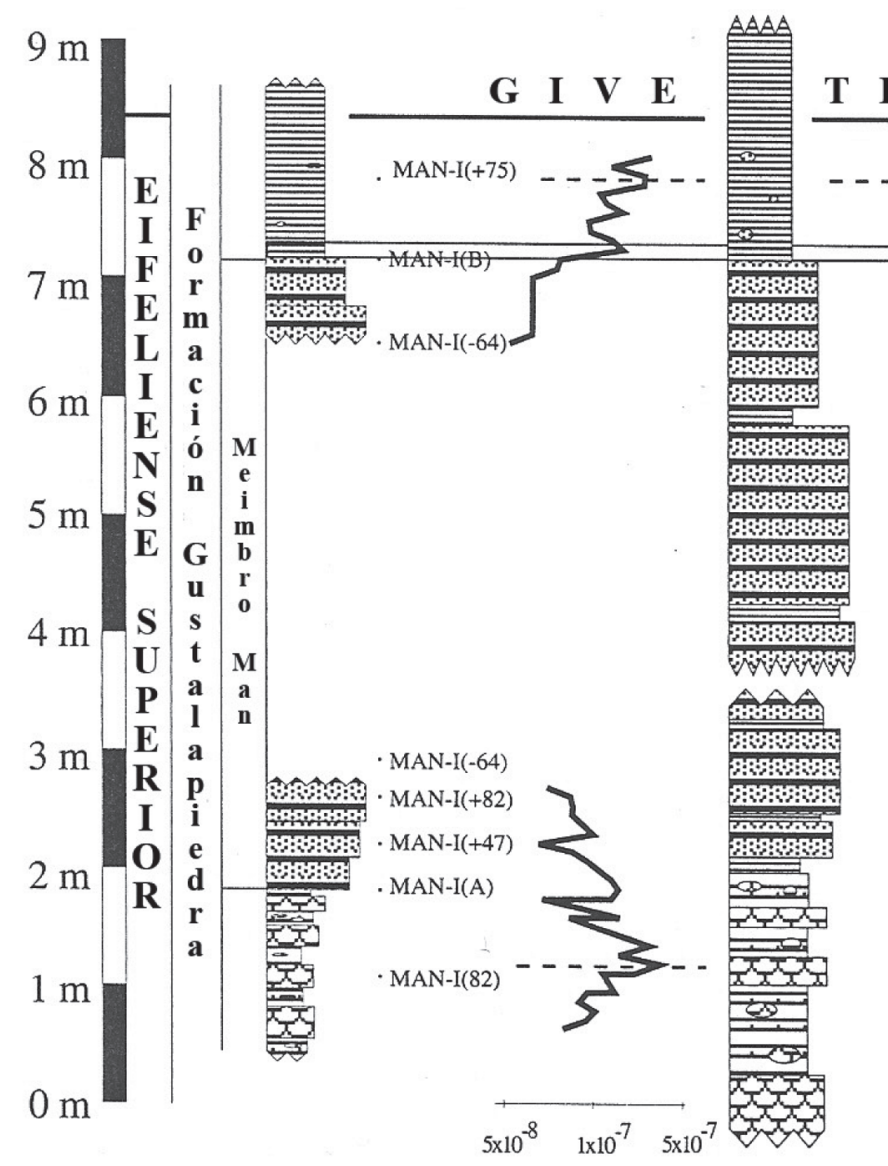

$\begin{array}{llll}\text { E } & \mathbf{N} & \mathbf{S} & \mathbf{E}\end{array}$
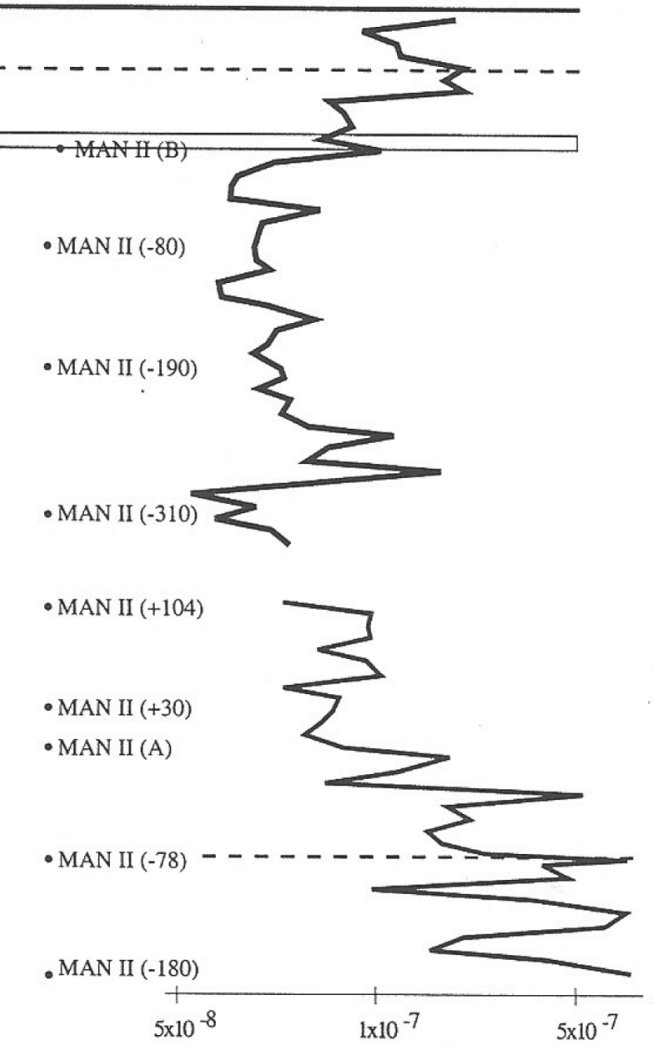

Límite operativo Eifeliense-Givetiense

- - - - _ - - . Límites del evento MSEC del Eifeliense Superior

Evento Kacak-Otomari

Figura 14: Correlación de las curvas MSEC obtenidas en dos secciones compuestas del Miembro Man de la Formación Gustalapiedra (Dominio Palentino, Palencia). A la izquierda, sección expuesta en la intersección con el Arroyo de Man de la pista que va desde la Abadía de Lebanza al Pico Linares. A la derecha, sección expuesta en la pista de descenso del Collado de La Pedrosa hacia el Arroyo de Man. En las curvas se aprecia un gran valle de valores negativos (entre líneas de trazos discontinuos) que representa el llamado «Evento del Eifeliense Superior» que comprende la posible situación del Evento Kacak-Otomari (barra rectangular blanca) y el limite operativo Eifeliense-Givetiense, algo por encima (trazo grueso continuo). A y B: niveles de referencia de base y techo de las limolitas del Mb. Man. Números negativos y positivos: distancias en cm por debajo y por encima de las muestras tomadas (MAN-I, MAN-II).

evidenciado en uno o dos niveles muy próximos del registro estratigráfico en la acumulación de enorme cantidad de conchas micromórficas (en torno a 1 $\mathrm{mm}$ de longitud) del braquiópodo terebratúlido Ense pumilio u otras especies próximas. El evento, se identificó también en Montagne Noire (SE de Francia), en el Tafilalt (Marruecos) y en Ougarta y Mouydir (S de Argelia). Como causa del mismo se seńaló un gigantesco maremoto que afectaría a las plataformas de Baltica y Gondwana en un área geográfica de más de $3000 \mathrm{~km}$ de extensión (Lottmann, 1990) (Fig. 15A). Como cabía esperar, la exploración detallada 


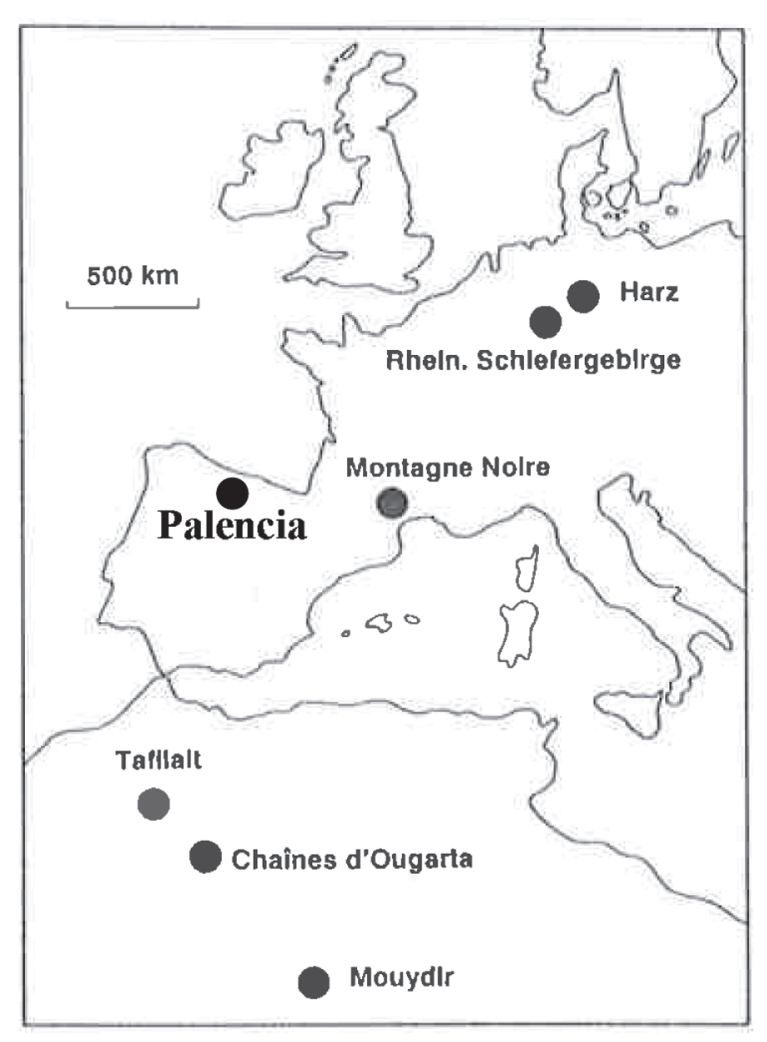

A
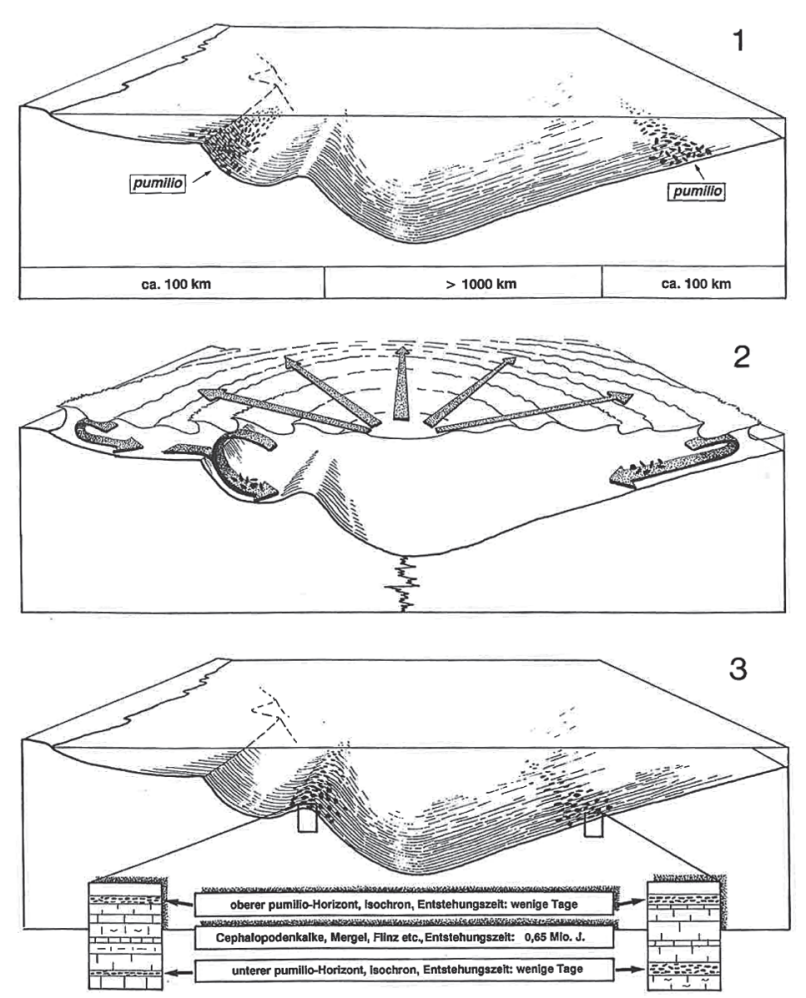

B

Figura 15: Hipótesis de Lottmann (1990) del desarrollo del Evento Pumilio, como generado por un gran maremoto. A) Regiones europeas y africanas donde se detectó el Evento Pumilio. B) Fases del fenómeno. 1: Antes del comienzo del maremoto. 2: Maremoto, propagación del mismo y mortalidad en masa de organismos micromórficos. 3: Depósito final de las conchas de los braquiópodos muertos (modificado de Lottmann, 1990).

del dominio facial pelágico de la Cordillera Cantábrica, situado en una posición paleogeográfica intermedia entre las regiones citadas, permitió encontrar, cerca del pueblo de Polentinos (Dominio Palentino) en capas de la edad adecuada de la Formación Cardaño (Figs. 6 y 16), una acumulación semejante de conchas micromórficas, pertenecientes a la especie Ense andrea, muy próxima a E. pumilio (Figs. 16 y 17A). Esta acumulación localizada en un nivel de unos centímetros de espesor, puede representar la consecuencia sedimentológica y biológica del paso del maremoto por el saliente iberoarmoricano de Gondwana y permite una correlación eventoestratigráfica de extraordinaria precisión, incluso circadiana. En cualquier caso, se requieren aún nuevos estudios sedimentológicos y bioquímicos para asegurar la causa del suceso. Un detalle marginal es que, en un nivel de una localidad cercana de edad parecida a la anterior, apareció un ejemplar solitario que, hasta hoy, es el único representante en Palencia de la importantísima familia de terebratúlidos Stringocephalidae, Parastringocephalus cf. dorsalis (Figs. 16 y 17B) (García-Alcalde, 2013). Las implicaciones paleobiogeográficas de este sorprendente hallazgo requieren la reevaluación de la ecología de la familia y de la comunicación entre las plataformas nord-gonwánicas durante el Givetiense.

8) Evento Pharciceras (Taghánico, PHE) (Fig. 6). Las alteraciones tectónicas impiden situar con precisión en el Dominio Palentino este evento que fue definido inicialmente en Norteamérica. Sin embargo, una parte de sus características son reconocibles aquí. Por ejemplo, todos los ammonoideos conocidos en la Formación Gustalapiedra (Figs. 6 y 7), salvo Tornoceras, desaparecieron en la parte alta de dicha formación, en la Biozona de conodontos Polygnathus varcus y la renovación subsiguiente, típica del even- 


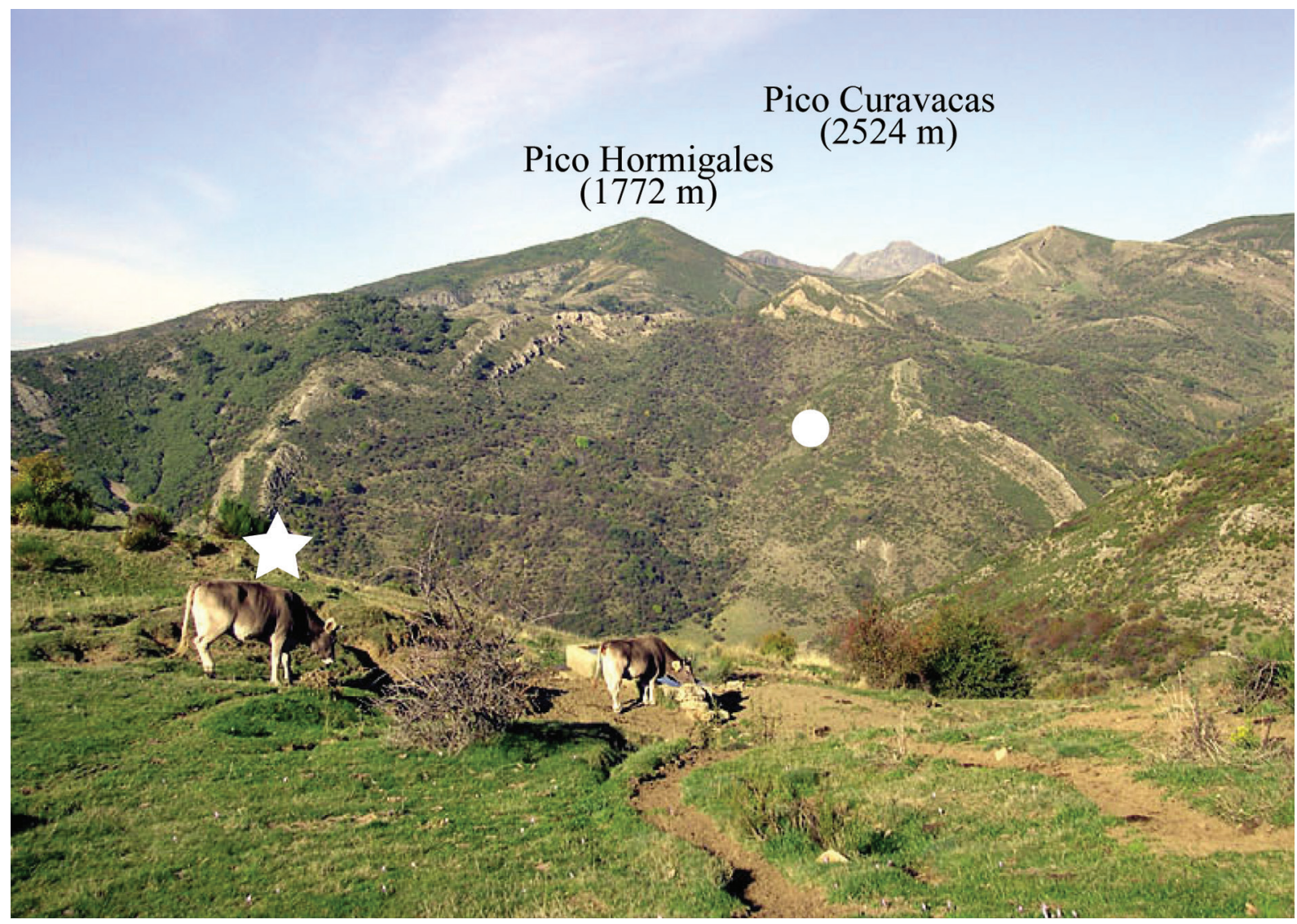

Figura 16: Vista de la ventana tectónica del arroyo de Man, desde el abrevadero del Collado de La Pedrosa (al oeste de Polentinos, Dominio Palentino). Estrella blanca: situación de las capas de la Formación Cardaño con Ense Andrea; Círculo blanco: Situación aproximada del yacimiento de Parastringocephalus cf. dorsalis, en la Fm. Cardaño.

to, basada en el desarrollo de farcicerátidos multilobulados (Pharciceras y Stenopharciceras), asociados con Mesobeloceras y Timanites (Figs. 7c, d), parece haberse completado en la parte final del miembro calizo inferior de la Fm Cardaño (Fig. 6), en la Biozona de conodontos Schmidtognathus hermanni inferior (Montesinos y Henn, 1986).

La crisis Taghánica se considera en la actualidad compuesta por varios eventos sucesivos, asociados con fluctuaciones eustáticas que ocurrieron durante un período de tiempo representado por las Biozonas de conodontos Polygnathus ansatus (parte superior) y Ozarkodina semialternans (Aboussalam, 2003; Brett et al., 2011).

La importancia del suceso es muy grande, hasta el punto de que se relaciona con la desaparición del Dominio paleogeográfico de las Américas Orientales (Boucot, 1990), causada por un cambio radical del gradiente climático global. Curiosamente, esta gran crisis pudo señalarse y caracterizarse mucho mejor en el Dominio nerítico Astur-Leonés (García-Alcalde, 1998a, García-Alcalde et al., 2001, García-Alcalde et al., 2011) que en el Palentino. En el dominio nerítico, los estudios de susceptibilidad magnética (García-Alcalde et al., 2011) (Fig. 18) parecen trazar la compleja y dilatada transgresión Taghánica causada por un gran cambio climático. Las consecuencias de esta transgresión para la fauna se manifiestan, sobre todo, en los organismos neríticos, principalmente braquiópodos (entre los que se observa la desaparición de todos los estringocefálidos y la extinción de más del $70 \%$ del resto de formas) y en la desaparición momentánea de la mayor parte de biostromos y biohermos de corales y estromatoporoideos.

9) Evento Frasnes (FE) (Fig. 6). Este evento se caracteriza por la extinción de la mayoria de ammonoideos farcicerátidos, todos los dacrioconáridos 


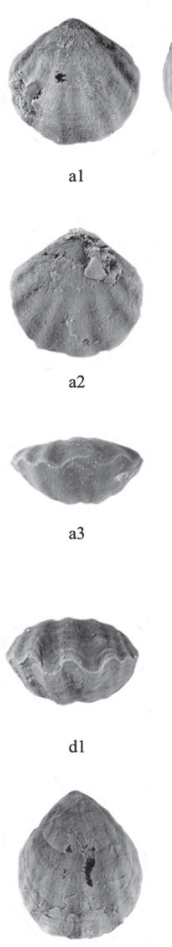

$\mathrm{d} 2$

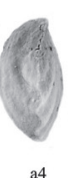

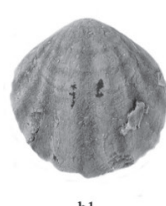

b1

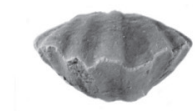

b4

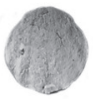

c1
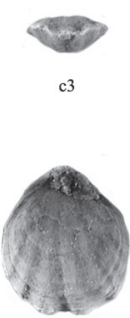

d3

d4

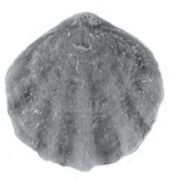

b2
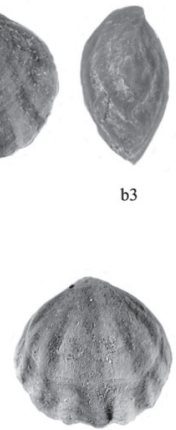

el

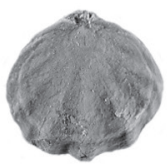

e3

e2

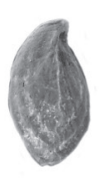

A

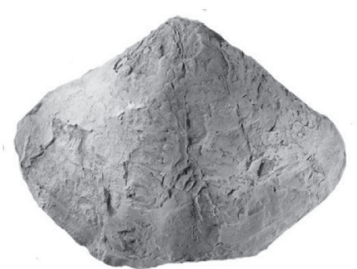

1
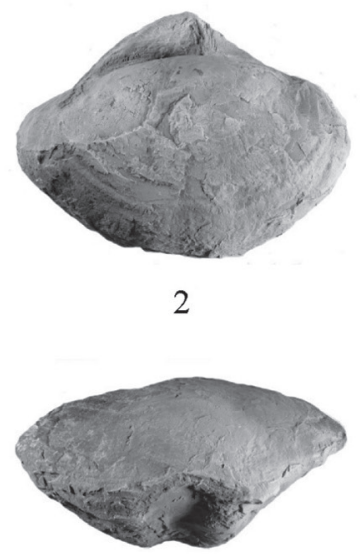

3

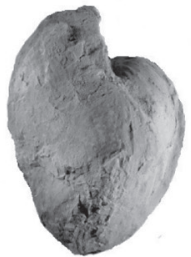

4

$20 \mathrm{~mm}$

Figura 17: A) Conchas micromórficas de Ense andrea Struve, 1992, Givetiense. a1, b1, c1, d2, e1: vistas ventrales; a2, b2, c2, d3, e3: vistas dorsales; a3, b4, c3, d1, e4: vistas anteriores, a4, b3, d4, e2: vistas laterales. B) Parastringocephalus cf. dorsalis (d'Archiac y Verneuil, 1842), Givetiense, 1-4: vistas ventral, dorsal, anterior y lateral.

Nowakiidae y muchos braquiópodos, corales y estromatoporoideos, extinción relacionada con una brusca transgresión marina global ocurrida hacia la Biozona de conodontos Polygnathus asymmetricus más baja. Aunque con dificultad, debido a causas tectónicas, el fenómeno puede reconocerse en el Dominio Palentino en la parte terminal del miembro calcáreo inferior de la Formación Cardaño (Fig. 6). La desaparición de las faunas mencionadas más atrás, antecede la presencia de una variada fauna de ammonoideos piritizados, con manticocerátidos, belocerátidos, tornocerátidos y triainocerátidos (Montesinos y Henn, 1986; Montesinos y SánzLópez, 1997).

10) Evento, o Eventos, Kellwasser (Kellwasser Inferior y Kellwasser Superior, LKE, UKE) (Fig. 6). Entre el Frasniense y el Carbonífero tuvieron lugar numerosos bioeventos, en particular el llamado Evento (o Eventos) Kellwasser que tuvo lugar en el Frasniense terminal y fue uno de los cinco principales en la historia del Fanerozoico.

El Evento Kellwasser se desarrolló en realidad, como un suceso bifásico. La primera fase (Kellwasser Inferior, LKE) se relaciona con una fuerte elevación del nivel de los mares, que se manifiesta en la entrada de lutitas negras o calizas arcillosas negras, como las que aparecen intercaladas en el miembro superior de calizas nodulosas de la Fm. Cardaño (Fig. 4C). Por su parte, la segunda etapa (Kellwasser Superior, UKE) se relaciona con un complejo proceso de fluctuación del nivel del mar en el que estuvieron involucrados un descenso brusco y acusado seguido de un repentino y marcado ascenso. En otras áreas, la segunda fase parece relacionada con el impacto de uno o varios bólidos extraterrestres. El resultado final del evento fue la total o casi total desaparición de ammonoideos, tentaculitoideos (tentaculítidos, dacrioconáridos y homocténidos) y organismos ben- 

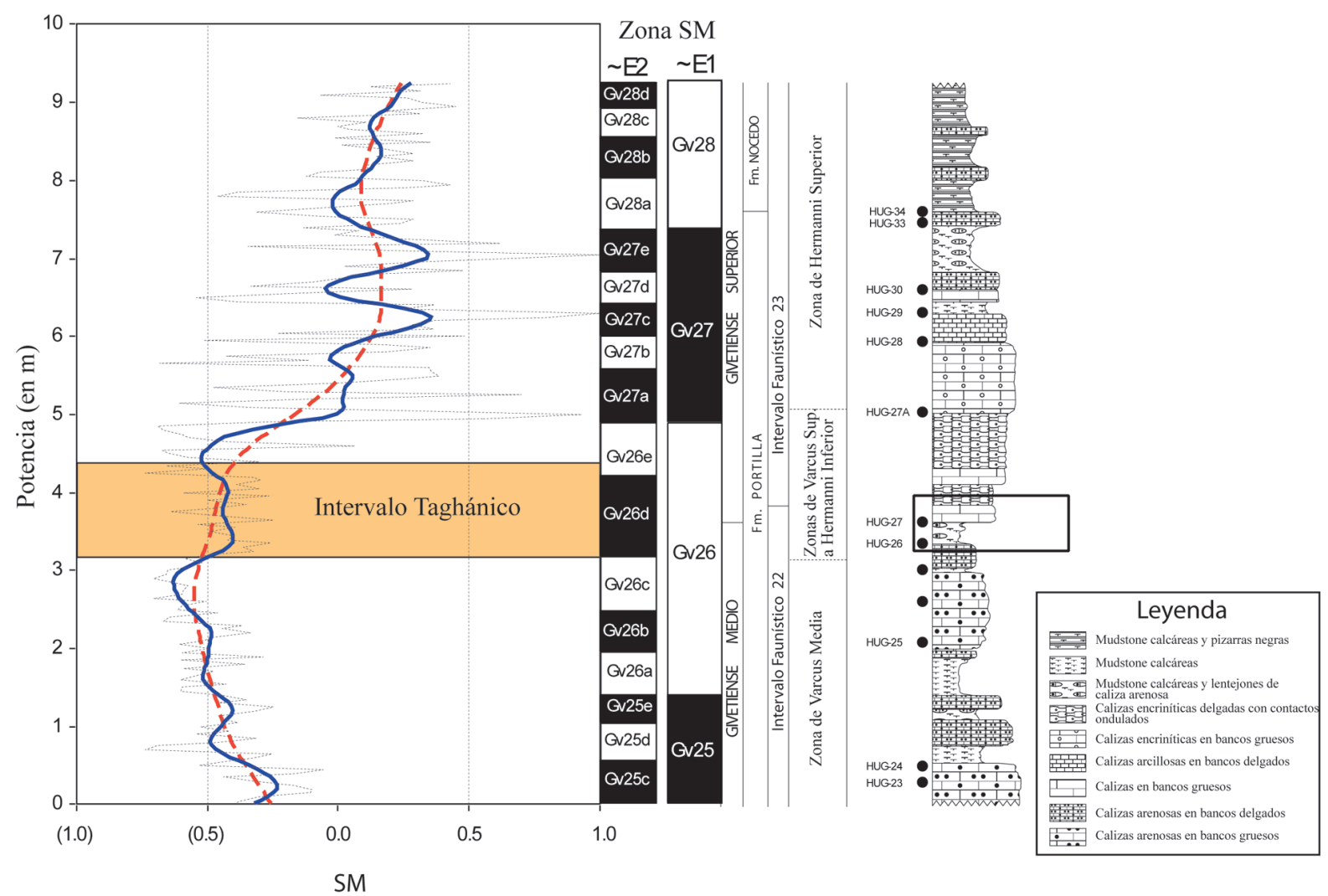

Figura 18: A la izquierda, curva MSEC del sector de la Formación Portilla representado en la columna de la derecha, entre los niveles HUG-26 y HUG-27. En la curva se pone de manifiesto la anomalía del Evento Taghánico. Datos obtenidos en la sucesión que aflora al sur de Huergas de Gordón (León, Dominio Astur-Leonés). Biozonas de conodontos, según García-López y Sánz-López (2002); Intervalos Faunísticos, según García-Alcalde (1996).

tónicos frasnienses (particularmente casi el 100\% de los braquiópodos atrípidos) y la eliminación virtual de los últimos arrecifes de corales y estromatoporoideos (cf. García-Alcalde, 1998a; Garcia-Alcalde et al., 2001).

En las áreas del Alto Carrión, Barruelo y Liébana, de la Provincia del Pisuerga-Carrión, los niveles estratigráficos correspondientes a la transición Frasniense/Fameniense están decapitados por los Mantos Palentinos, extremadamente tectonizados o faltan. En cambio aparecen bien representados en algunos de los cortes de la unidad de Montó, en la provincia de León. Allí, la crisis se desarrolló en el intervalo entre las biozonas de conodontos Palmatolepis rhenana superior (LKE) y Palmatolepis linguiformis (UKE) (Sánz-López et al., 1999a). Inmediatamente sobre el nivel de extinción, en la parte terminal de la Fm. Cardaño (Fig. 6), aparecieron nuevas formas de trilobites, entre ellas, Tri- merocephalus y Cryphops (Fig. 9) y ammonoideos: Falcitornoceras, Phoenixites y Aulatornoceras (Montesinos y Sanz-López, 1997).

11) Eventos del Fameniense, post-Evento Kellwasser (Fig. 6). Un conjunto bastante numeroso de eventos, supuestamente globales, se definieron en facies pelágicas a lo largo del Fameniense y parte más baja del Carbonífero, quizás relacionados con aspectos ecológicos cambiantes inducidos por las nuevas condiciones dinámicas de la Orogenia Varisca. Los más conocidos son los llamados, de más antiguo a más moderno, Condroz (CE), Enkeberg (EE), Annulata (AE) y Hangenberg (HE) (Fig. 6). Habitualmente, la impronta litológica de tales eventos viene oscurecida por la variedad de situaciones paleogeográficas que coexisten en regiones próximas durante la orogenia, y la biológica suele caracterizarse casi exclusivamente por cambios en las faunas de ammonoideos. 
La escasez de afloramientos palentinos con sucesiones famenienses completas y su intensa deformación tectónica no permiten la identificación precisa de los eventos, pero hay indicios para situarlos de manera aproximada. La Formación Cardaño, donde tuvieron lugar los Eventos Kellwasser, es seguida, sucesivamente, por las formaciones Murcia y Vidrieros (Fig. 6). En los finos lechos de lutitas negras intercaladas en la Fm. Murcia se hallaron faunas enanas piritizadas de los ammonoides Cheiloceras y Falcitornoceras, bivalvos como Guerichia, Praecardium y otros, braquiópodos: Ptychomaletoechia, Chonetipustula, Lingulipora y otros y trilobites tales como Ductina y Trimerocephalus (Fig. 9). Formas piritizadas de Cheiloceras cf. amblylobum y C. planilobum, prevalecen hasta la misma base de la Fm. Vidrieros, sugiriendo el Evento Condroz (CE) inferior. Más arriba, desaparece una abundante y variada fauna de ammonoideos en la que están comprendidos los géneros Cheiloceras, Lobotornoceras, Sporadoceras, Maeneceras y Dimeroceras (Kullmann, 1960, Montesinos y Arbizu, 1987), lo que parece indicar la etapa superior del Evento Enkeberg (EE). Por encima, aparecen Platyclymenia (Platyclymenia) annulata y otros climénidos (Montesinos y Arbizu, 1987), insinuando el Evento Annulata (EA). Al mismo nivel, se citaron también varias especies de Falciclymenia, Sporadoceras y Prionoceras (Prionoceras) (Kullmann, 1960). El Evento Hangenberg, podría estar representado por la presencia de ammonoideos de la Genozona de Wocklumeria (imitocerátidos, Kalloclymenia y Cymaclymenia) (Kullmann, 1960) en la base de la Fm. Vegamián (Fig. 6) por encima inmediatamente de capas con conodontos de las Zonas Siphonodella praesulcata Media y Superior (Raven, 1983).

\section{Conclusiones}

El Dominio Palentino, o Región del Pisuerga-Carrión, presenta características muy notables diferenciadas de las del resto de la Cordillera Cantábrica tanto en aspectos paleogeográficos como estructurales.

Desde el punto de vista paleogeográfico, la situación del ámbito Palentino ocupando una posición distal en la antigua plataforma devónica, permitió el desarrollo de facies y asociaciones fosilíferas completamente originales frente a las del resto de la Zona
Cantábrica, propias de sectores proximales de la misma plataforma. Debido a su situación relativamente más alejada del área fuente la sucesión preorogénica palentina del Devónico está muy condensada frente a la Astur-Leonesa. Además, sus faunas características corresponden a organismos pelágicos planctónicos y epiplanctónicos (dacrioconáridos, homocténidos y ciertos trilobites y braquiópodos) y nectónicos (ammonoideos y muchos trilobites). Este es uno de los principales puntos fuertes geológicos de la región: como la estratigrafía moderna del Devónico y la investigación de los principales bioeventos se apoya esencialmente en fósiles y series estratigráficas pelágicas, la identificación de límites cronoestratigráficos es mucho más precisa en el Dominio Palentino que en el Astur-Leonés.

El otro gran punto fuerte deriva de un nuevo fenómeno de distalidad, pero esta vez referido no a la situación en el dominio marino, sino en el propio $\mathrm{Ma}-$ cizo Ibérico, cuyo extremo ocupa el área Palentina. La onda orogénica Varisca produjo dos importantes fenómenos. En primer lugar, merced a la escasa competencia de las sucesiones siluro-devónicas compuestas, en buena medida, por rocas siliciclásticas finas, lutíticas, de gran plasticidad, comenzó el desplazamiento durante el Serpujoviense-Bashkiriense de los Mantos Palentinos, procedentes posiblemente de un área de la Zona Asturoccidental-Leonesa situada al sudoeste. Esta gran placa, alcanzó y superó el ámbito de la Zona Cantábrica pasando en último extremo por encima del apilamiento antiformal del Domo del Valsurvio hasta emplazarse en la Provincia del Pisuerga-Carrión (Fig. 1). En el curso del desplazamiento, los Mantos Palentinos se desgajaron de sus raíces y quedaron aislados del contexto regional que les correspondía, oculto hoy bajo la espesa sucesión sedimentaria de la Meseta castellana. Tras estos mantos, otras unidades cabalgantes, esa vez procedentes de áreas más proximales de la Zona Cantábrica, se movieron a lo largo del Carbonífero, hacia la misma región: Somiedo-Sobia-Correcillas, Esla y Bodón-Ponga (Fig. 1), algunas de ellas aportando extensas cuñas clásticas a la cuenca sinorogénica palentina. Por último, a fines del Carbonífero cambió la dirección de los esfuerzos y se produjo un desplazamiento hacia el sudeste del conjunto de láminas que constituyen hoy día los Picos de Europa. Estos nuevos empujes deformaron aún más el Dominio 
Palentino y contribuyeron de forma decisiva a la formación del Arco Ibero-Armoricano, en particular de su núcleo cantábrico: el Arco Astúrico. El estrujamiento extremo de la Provincia del Pisuerga-Carrión causado por esta dinámica (recuérdese la imagen de las excavadoras), originó modelos tectonosedimentarios variados y originales lo que convierte a la región en un auténtico paradigma geológico para comprender el comportamiento de los márgenes de macizos.

Los aspectos destacados atrajeron en los últimos tiempos hacia la montańa Palentina a una pléyade de investigadores que antes la encontraban, simplemente, demasiado lejana y recóndita. El sentimiento pionero, del que disfrutamos durante muchos años, ha dejado paso a otro sentimiento más complejo, pero también muy gratificante: la Zona Cantábrica en general, pero el Dominio Palentino en particular para los aspectos señalados más atrás se están convirtiendo en una referencia esencial para la comunidad científica internacional dedicada al estudio de los fenómenos Variscos. Perdimos intimidad pero ganamos en sabiduría.

\section{Agradecimientos}

Dedico este trabajo a mi amigo y compañero Profesor Alberto Marcos Vallaure, con motivo de su jubilación oficial, como prueba de afecto y profunda admiración a su labor científica. Este trabajo es una contribución a los proyectos MINECO CGL 2011-24775 y Correlación Geológica Internacional, IGCP 596 «Climate change and biodiversity patterns in the Mid-Palaeozoic (Early Devonian to late Carboniferous)». El trabajo se benefició de lecturas críticas realizadas por los profesores Juan Luis Alonso y Josep Poblet, del Departamento de Geología de Oviedo, a quienes estamos sumamente reconocidos; agradecemos también al primero de los investigadores citados la cesión de la Figura 1 de esta publicación. Las imprecisiones y errores que aún puedan existir son de la exclusiva responsabilidad del autor. Gracias también a los profesores Montserrat Truyols Massoni y Miguel Arbizu, del Departamento de Geología de Oviedo, y Román Montesinos, de la Universidad de La Coruña por la cesión de fotografías de dacrioconáridos, trilobites y ammonoideos, de sus respectivos trabajos de investigación, para ilustrar este trabajo. Y, naturalmente, un total reconocimiento a la minuciosa revisión del manuscrito del trabajo, por las doctoras Elisa Villa, del Departamento de Geología de Oviedo, y Ángela Suárez, del Instituto Geológico y Minero de España.

\section{Bibliografía}

Aboussalam, Z. S. (2003): Das «Taghanic-Event» im höheren Mittel-Devon von West-Europa und Maroko. Münstersche Forschungen zur Geologie und Paläontologie, 97: 1-332.

Adrichem-Boogaert, H. A. van (1967): Devonian and Lower Carboniferous conodonts of the Cantabrian Mountains (Spain) and their stratigraphic application. Leidse Geologische Mededelingen, 39: 129192.

Alonso, J. L., Marcos, A. y Suárez, A. (2009): Paleogeographic inversion resulting from large out of sequence breaching trusts: The León Fault (Cantabrian Zone, NW Iberia). A new picture of the external Variscan Thrust Belt in the Ibero-Armorican Arc. Geologica Acta, 7(4): 451-473.

Alonso, J. L., Pulgar, F. J., García-Ramos, J. C. y Barba, P. (1996): Tertiary Basins and Alpine Tectonics in the Cantabrian Mountains, en Friend, P. F. y Dabrio, C. J. (eds.): Tertiary basins of Spain: the stratigraphic record of crustal kinematics. Cambridge University Press, 214-227.

Aramburu, C., Truyols, J., Arbizu, M., Méndez-Bedia, I., Zamarreño, I., García-Ramos, J. C., Suárez de Centi, C. y Valenzuela, M. (1992): El Paleozoico Inferior de la Zona Cantábrica, en Gutiérrez-Marco, J. G., Saavedra, J. y Rábano, I. (eds.): Paleozoico Inferior de Ibero-Armorica, Universidad de Extremadura, Badajoz, 397-421.

Arbizu, M. (1977): Asteropyginae (Trilobita) du Dévonien des Montagnes Cantabriques (Espagne). Bulletin de la Société Géologique et Minéralogique de Bretagne, C, 9(2): 1-102.

Arbizu, M. (1985): Trilobites Phacopinae de la Formación Vidrieros en el área de Gildar-Montó (León, 
NO de España) y su distribución estratigráfica. Trabajos de Geología, 15: 67-75

Arbizu, M. (2001): Trilobites de la Cordillera Cantábrica y eventos geológicos. Boletín de la Sociedad Entomológica Aragonesa, 28: 1-14.

Becker, G. (1981): Ostracoda aus cephalopoden-führendern oberdevon im Kantabrischen Gebirge (N-Spanien). 1. Hollinacea, Primitiopsacea, Kirkbyacea, Healdiacea und Bairdiocypridacea. Palaeontographica, A, 173 (1-4): 1-63.

BinneKamp. J. (1965): Lower Devonian brachiopods and stratigraphy of North Palencia (Cantabrian Mountains, Spain). Leidse Geologische Mededelingen, 33: 1-62.

Boucot, A. J. (1990): Silurian and pre-Upper Devonian bio-events, en Kaufman, E. G. y Walliser, O. H. (eds.): Extinction Events in Earth History. Lecture Notes in Earth Sciences, 30: 125-132.

Brett, C. E., Baird, G. C., Bartholomew, A. J., DeSanctis, M. K. y Ver Straeten, C. A. (2011): Sequence stratigraphy and a revised sea-level curve for the Middle Devonian of eastern North America. Palaeogeography, Palaeoclimatology, Palaeoecology, 304: 21-53.

Carls, P. (1983): La Zona Asturoccidental-Leonesa en Aragón y el Macizo del Ebro como prolongación del Macizo Cantábrico, en Comba, J. A. (coord.): Volumen Jubilar J. M. Ríos. Instituto Geológico y Minero de España, 11-32.

Colmenero, J. R., Fernández, L. P., Moreno, C., Bahamonde, J. R., Barba, P., Heredia, N. y GonzÁlez, F. (2002): Carboniferous, en Gibbons, W. y Moreno, M. T. (eds.): The Geology of Spain. Geological Society, London, 93-116.

Crick, R. E., Ellwood, B. B., el Hassani, A., Feist, R. y Hladil, J. (1997): Magneto-Susceptibility event and cyclostratigraphy (MSEC) of the Eifelian-Givetian GSSP and associated boundary sequences in North Africa and Europe. Episodes, 20: 167-175.
Ellwood, B. B., Benoist, S. L., el Hassani, A., Wheeler, C. y Crick, R. E. (2003): Impact ejecta layer from the Mid-Devonian: possible connection to global mass extinctions. Science, 300: 1734-1737.

Ellwood, B. B., Crick, R. E., García-Alcalde, J. L., Soto, F. M., Truyols-Masssoni, M., el HasSANI, A. y Kovas, E. J. (Ned) (2001): Global correlation using magnetic susceptibility data from Lower Devonian rocks. Geology, 29(7): 583-586.

Ellwood, B. B., García-Alcalde, J. L., el Hassani, A., Hladil, J., Soto, F. M., Truyols-Massoni M., Weddige, K. y Koptikova, L. (2006): Stratigraphy of the Middle Devonian boundary: Formal definition of the susceptibility magnetostratotype in Germany with comparisons to sections in the Czech Republic, Morocco and Spain. Tectonophysics, 418: 31-49.

Espina, R. G. (1994): Extensión mesozoica y acortamiento alpino en el borde occidental de la Cuenca Vasco Cantábrica. Cuadernos do Laboratorio Xeolóxico de Laxe, 19: 137-150.

Frankenfeld, H. (1983): El Manto de MontóArauz: interpretación estructural de la región del Pisuerga-Carrión (Zona Cantábrica, NW de España). Trabajos de Geología, 13: 37-47.

Gallastegui, J. (2000): Estructura cortical de la Cordillera y Margen Continental Cantábricos: perfiles ESCI-N. Trabajos de Geología, 22: 9-231.

García-Alcalde, J. L. (1996): El Devónico del Dominio Astur-Leonés en la Zona Cantábrica ( $\mathrm{N}$ de España). Revista Española de Paleontología, número extraordinario: 58-71.

García-Alcalde, J. L. (1997): North Gondwanan Emsian events. Episodes, 20 (4): 241-246.

García-AlCalde, J. L. (1998a): Devonian events in Northern Spain. Newsletter in Stratigraphy, 36(2/3): 157-175.

García-Alcalde, J. L. (1998b): Braquiópodos Rinconélidos del Lochkoviense (Devónico Inferior) de la Cordillera Cantábrica (Norte de España). Géobios, 31(6): 767-789. 
García-Alcalde, J. L. (2004): Lower Devonian Delthyridoidea (Brachiopoda, Delthyrididina) of the Cantabrian Mountains (N Spain). Bulletin de l'Institut royal des Sciences Naturelles de Belgique, 74, supplement: 9-38.

García-Alcalde, J. L. (2010): Givetian brachiopod faunas of the Palentian Domain (N Spain). Revista Española de Paleontología, 25(1): 43-69.

García-Alcalde, J. L. (2013): Terebratúlidos (braquiópodos) del Devónico de la Cordillera Cantábrica (N de España). Trabajos de Geología, 33: 17-170.

García-Alcalde, J. L. (2014): Beethovenia n. gen. y Plicostropheodonta Sokolskaya, 1960 (Strophodontidae Caster, 1939), del Devónico Inferior de Europa occidental. Trabajos de Geología, 34: 19-60.

García-Alcalde, J. L., Arbizu, M., GarcíaLópez, S., Leyva, F., Montesinos, R., Soto, F. y Truyols-Massoni, M. (1990a): Devonian stage boundaries (Lochkovian/Pragian, Pragian/Emsian, and Eifelian/Givetian) in the Cantabric region (NW Spain). Neues Jahrbuch Geologie und Paläontologie Abhandlungen, 1980(2): 177-207.

García-Alcalde, J. L., Arbizu, M. y Truyols-Massoni, M. (2001): Extinciones masivas en el Devónico, en Gámez, J. A. y Liñán, E. (eds.): La Era Paleozoica. El desarrollo de la vida marina. Homenaje al Profesor Jaime Truyols, Memorias de las VII Jornadas Aragonesas de Paleontologia, Institución «Fernando El Católico», Diputación de Zaragoza, 125-145.

García-Alcalde, J. L., Ellwood, B. B., Soto, F., Truyols-Masoni, M. y Tomkin, J. H. (2011): Precise timing of the Upper Taghanic Biocrisis, Geneseo Biovevent, in the Middle-Upper Givetian (Middle Devonian) boundary in Northern Spain using biostratigraphic and magnetic susceptibility data sets. Palaeogeography, Palaeoclimatology, Palaeoecology, 313: 26-40.

García-Alcalde, J. L., Montesinos, J. R., Truyols-Massoni, M., García-López, S., Arbizu, M. A. у Sото, F. (1988): El Silúrico y el Devónico del Dominio Palentino (NO de España). Revista de la Sociedad Geológica de España ,1(1-2): 7-13.
García-Alcalde, J. L., Montesinos, J. R., Truyols-Massoni, M., García-López, S., Arbizu, M. A. y Soto, F. (1990b): The Palentine Domain (Palentian Zone), en Dallmeyer, R. D. y MartínezGarcía, E. (eds.): Pre-Mesozoic Geology of Iberia. Springer Verlag, 20-23.

García-Alcalde, J. L., Soto, F. y Truyols-MassOnI, M. (2002): Cantabrian Mountains, en Gibbons, W. y Moreno, T. (eds.): The Geology of Spain. The Geological Society, 68-76.

García-López, S., Jahnke, H. y Sanz-López, J. (2002): Uppermost Pridoli to Upper Emsian stratigraphy of the Alto Carrión Unit, Palentine Domain (Northwest Spain), en García-López, S. y Bastida, F. (eds.): Palaeozoic Conodonts from northern Spain. 8 International Conodont Symposium, ECOS VIII, Cuadernos del Museo Geominero, 1: 229-257.

García-López, S. y SÁnz-López, J. (2002): Devonian to Lower Carboniferous conodont biostratigraphy of the Bernesga valley section (Cantabrian Zone, NW Spain, en García-López, S. y Bastida, F. (eds.): Palaeozoic Conodonts from northern Spain. 8 International Conodont Symposium, ECOS VIII, Cuadernos del Museo Geominero, 1: 163-205.

Harrington, H. J., Henningsmoen, G., Howell, B. F., JaAnusson, V., Lochman-Dolk, C., Moore, R. C., Poulsen, C., Rasetti, F., Richter, E., Richter, R., Schmidt, H., Sdzuy, K., Struve, W., Stubblefield, C. J., Tripp, R., Weller, J. M. y Whittington, H. B. (1959): Trilobita, en R. C. Moore (editor): Treatise on Invertebrate Paleontology, part, O, Arthropoda, 1, 38-560.

Heredia, N., Rodríguez Fernández, L. R. y WagNER, R. H. (1990): Carboniferous of the Palentian Zone, en Dallmeyer, R. D. y Martínez-García, E. (eds.): Pre-Mesozoic Geology of Iberia. Springer Verlag, 34-38.

Jahnke, H., Henn, A., Mader, H. y SchweineBERG, J. (1983): Silur und Devon im Arauz-Gebiet (Prov. Palencia, N-Spanien). Newsletter in Stratigraphy, 13(1): 40-66.

Johnson, J. G., Klapper, G. y Sandberg, C. A. (1985): Devonian eustatic fluctuations in Euramer- 
ica. Bulletin of the Geological Society of America, 96: 567-587.

Julivert, M. (1971): Décollement tectonics in the Hercynian cordillera of NW Spain. American Journal of Science, 270: 1-29.

Kanis, J. (1956): Geology of the eastern zone of the Sierra del Brezo (Palencia, Spain). Leidse Geologische Mededelingen, 21(2): 377-445.

Kullmann, J. (1960): Die Ammonoidea des Devon im Kantabrischen Gebirge (Nordspanien). Akademie Wissenschaften u. Lit. Abhandlungen, Mathematisch-naturwissenchafen klass, 1960(7): 1-105.

Lottmann, J. (1990): Die pumilio-Events (Mittel Devon). Göttinger Arbeiten zur Geologie und Paläontologie, 44, 1-98.

Mader, H. (1986): Schuppen und zahne von Acanthodien und Elasmobranchien aus dem Unter-Devon Spaniens (Pisces). Göttinger Arbeiten zur Geologie und Paläontologie, 28: 1-59.

Marquínez, J. y Marcos, A. (1984): La estructura de la Unidad del Gildar-Montó (Cordillera Cantábrica). Trabajos de Geología, 14: 53-64.

Martín-Merino, G., Fernández, L. P., ColmenERO, J. R. y BaHAmonde, J. R. (2014): Mass-transport deposits in a Variscan wedge-top foreland basin (Pisuerga area, Cantabrian Zone, NW Spain). $M a-$ rine Geology, 356: 71-87.

Montesinos, R. (1987): Agoniatitina y Anarcestina del Devónico Medio de la Cordillera Cantábrica (Dominios Palentino y Asturleonés, NO de España). Cuadernos do Laboratorio Xeolóxico de Laxe, 12: 99-118.

Montesinos, R. (1988): Ammonoideos del Devónico de España. Tesis Doctoral, Universidad de Oviedo, 180 p.

Montesinos, R. (1991): Ammonoideos de las Capas de Vañes (Formación Abadía, Devónico inferior) del Dominio Palentino (Palencia, NO de España). Cuadernos do Laboratorio Xeolóxico de Laxe, 16: 193-201.
Montesinos, J. R. y Henn, A. H. (1986): La Fauna de Pharciceras (Ammonoidea) de la Formación Cardaño (Dominio Palentino, Cordillera Cantábrica, NO de España). Trabajos de Geología, 16: 61-76.

Montesinos, J. R. y Arbizu, M. A. (1987): Ammonoideos y trilobites de la Formación Vidrieros (Horcada del Oro, Dominio Palentino, NO de España). Cuadernos do Laboratorio Xeolóxico de Laxe, 12: 93-98.

Montesinos, R. y SÁnz-López, J. (1997): Los ammonoideos de la parte superior de la Formación Cardaño (unidad del Gildar-Montó, NE de la provincia de León, España) y su aplicación a la bioestratigrafía del Devónico Superior. Revista Española de Paleontología, 12(2): 243-248.

Pulgar, J. A., Alonso, J. L., Espina, R. G. y Marin, J. A. (1999): La deformación alpina en el basamento varisco de la Zona Cantábrica. Trabajos de Geología, 21: 283-294.

Raven, J. G. M. (1983): Conodont biostratigraphy and depositional history of the Middle Devonian to Lower Carboniferous in the Cantabrian Mountains, Spain. Leidse Geologische Mededelingen, 52(2): 265339.

Rodríguez Fernández, L. R. y Heredia, N. (1987): La estratigrafía del Carbonífero y la estructura de la Unidad del Pisuerga-Carrión, NO de España. Cuadernos do Laboratorio Xeolóxico de Laxe, 12: 207-229.

Rodríguez Fernández, L. R. y Heredia, N. (1988): Evolución tectonosedimentaria de una cuenca de antepaís ligada a una cadena arqueada: el ejemplo de la unidad del Pisuerga- Carrión (Zona Cantábrica, NO de España). II Congreso Geológico de España, Simposios, 65-74.

Rodríguez Fernández, L. R., Barba, P., Heredia, N., Navarro, D., Martínez, E., Marquínez, J., Alonso Herrero, E., Gallastegui, G. (1994): Mapa y memoria explicativa de la Hoja n. 81 (Potes) del Mapa geológico Nacional a escala 1:50.000 (2. ${ }^{\text {a }}$ serie). Instituto Geologico y Minero de España, Madrid. 
Sanz López, J., García-López, S. y Montesinos, J. R. (1999a): Conodontos del Frasniense superior y Fameniense inferior de la Formación Cardaño (unidad del Gildar-Montó, Dominio Palentino, Zona Cantábrica). Revista Española de Paleontología, 14(1): 25-35.

Sanz-López, J., García-López, S., Montesinos, J. R. y Arbizu, M. (1999b): Biostratigraphy and sedimentation of the Vidrieros Formation (middle Famennian-lower Tournaisian) in the Gildar-Montó unit (northwest Spain). Bollettino della Socièta Paleontologica Italiana, 37(2-3): 393-406.

Schöne B. R., Basse, M. y May, A. (1998): Korrelationen des Eifelium/Givetium Grenzbereichs im Rheinischen Schiefergebirge. Senckenbergiana lethaea, 77(1/2): 233-242.

Schweineberg, J. (1987): Silurische Chitinozoen aus der provinz Palencia (Kantabrisches Gebirge, N-Spanien). Göttinger Arbeiten zur Geologie und Paläontologie, 33: 1-94.

Smeenk, Z. (1983): Devonian trilobites of the southern Cantabrian Mountains (Northern Spain) with a systematic description of the Asteropyginae. Leidse Geologische Mededelingen, 52(2): 383-511.

Soto, F., Fernández, L. P., Fernández-Martínez, E., García-Alcalde, J. L., Méndez-Bedia, I., Truyols-Massoni, M. y Vera de la Puente, C. (2007): The first reefal episode (Earliest Pragian) in the Cantabrian Zone (NW Spain) and its relationship with the Lochkovian-Pragian Boundary Event. Actas X International Congress on Fossil Cnidaria and Porifera, 85.
Soto, F. y Kullmann, J. (1996): Hornförmige einzelkorallen (Rugosa) von typ der "Cyathaxonia-Fauna" im Unter-Emsium des östlichen Kantabrischen Gebirges, NW-Spanien. Geobios, 29(6): 651-669.

STruve, W. E. (1982): The great gap in the record of marine Middle Devonian. Courier Forschungsinstitut Senckenberg, 55: 433-448.

Truyols-Massoni, M. (1988): Dacrioconáridos y Homocténidos del Devónico de España (Cordillera Cantábrica y otras áreas). Tesis Doctoral, Universidad de Oviedo, 269 p.

Truyols-Massoni, M. (1989): Devonian Homoctenids of the Cantabrian Zone (NW Spain): an attempt of biozonation. Géobios, 22(5): 671-676.

Truyols-Massoni, M. (1999a): La edad de las capas con Mimosphictes en el Devónico de la Cordillera Cantábrica (NW de España). Trabajos de Geología, 21: 377-384.

Truyols-Massoni, M. (1999b): El género Undastriatostyliolina en la Cordillera Cantábrica (NO de España). Sistemática, evolución y paleobiogeografía. Revista Española de Paleontología, n. ${ }^{\circ}$ extra, homenaje J. Truyols: 239-249.

Truyols-Massoni, M., Montesinos, R., García-Alcalde, J. L. y Leyva, F. (1990): The Kacak-Otomari event and its characterization in the Palentine Domain (Cantabrian Zone, NW Spain), en Kauffman, E. G. y Walliser, O. H. (eds.): Extinction Events in Earth History. Lecture Notes in Earth Science, 30: 133-143. 
